\title{
LA ECONOMÍA Y ALGO DE LA POLÍTICA EXTERIOR DE LA UNIÓN EUROPEA
}

\section{THE ECONOMY AND SOME FOREIGN POLICY OF THE EUROPEAN UNION}

Carlos Díaz Gómez: Universidad de Alcalá de Henares. Madrid (España) carlos_diazgomez@yahoo.com

\section{CURRÍCULUM VITAE}

Doctor en Filosofía por la Universidad Complutense de Madrid (España) con Premio Extraordinario, Licenciado en Derecho por la Universidad Complutense de Madrid (España) con Premio Extraordinario, Licenciado en Altos Estudios Constitucionales con Premio Extraordinario y Profesor de la Universidad Complutense de Madrid (España). Autor de numerosos libros y artículos en revistas especializadas y universitarias.

\section{RESUMEN}

La Unión Europea es una comunidad política de Derecho constituida en régimen de organización internacional. En ella se acogen los pueblos y estados de Europa, 27 en total. Entró en vigor con el Tratado de la Unión Europea el 1 de noviembre de 1993. La propia Unión Europea ha desarrollado un sistema jurídico y político, único en el mundo, que se rige por mecanismos y procedimientos de funcionamiento internos complejos que, con el tiempo, han conformado un sistema de gobierno transnacional que combina elementos de cooperación multilateral con otros de vocación 
supranacional. En la Unión Europea existe un afán integrador por medio de políticas comunes que abarcan distintos ámbitos, el más importante y del que se parte, el económico.

\title{
PALABRAS CLAVE
}

Unión Europea - Economía - Políticas Comunes - Política Exterior

\begin{abstract}
The European Union is a political community of law regime established in international organization. It host peoples and states of Europe, 27 in total. Entered into force with the Treaty on European Union on 1 November 1993. The EU itself has developed a legal and political system, unique in the world, governed by mechanisms and complex internal operating procedures that, over time, have formed a transnational governance system that combines elements of multilateral cooperation with other supranational vocation. In the EU there is a desire by integrating common policies covering different areas, the most important and which are partly economic.
\end{abstract}

\section{KEY WORDS}

European Union - Economy - Common Policies - Foreign Policy 


\section{TEXTO}

La actual Unión Europea es un "club" exclusivo -estructura política, le llama el glosario de política monetaria del Banco de España- de 27 miembros. Cada uno de los cuales tiene su particular legislación contable, mercantil, laboral y fiscal. No han faltado intentos por homogeneizar el marco legal en aras de conseguir un auténtico mercado único. Pero los avances han sido escasos.

Así, "los fondos de pensiones...no pueden ofrecer sus servicios en un Estado miembro distinto del suyo" (Melgarejo, 2002, p. 115).

De modo que la supuesta y predicada libertad de establecimiento empresarial se convierte más en una declaración de principios que en una realidad efectiva. Una cantidad considerable de decretos, leyes y reglamentos de los distintos países impiden esa supuesta libertad de establecimiento o la limitan de modo esencial. Por ejemplo, el Gobierno francés aprobó el pasado mes de diciembre de 2005 un decreto NOTA 1 muy restrictivo y regulador que afecta a nada menos que once sectores "estratégicos" de la economía gala, y que suscitó, como es lógico, el recelo de la Comisión.

Francia se defiende alegando que no es, ciertamente, el único país o estado que promueve sus barreras de entrada.

De igual modo, el artículo 296 b) del Tratado constitutivo de la Unión Europea establece que «todo Estado miembro podrá adoptar las medidas que estime necesarias para la protección de los intereses esenciales de su seguridad y que se refieran a la producción o al comercio de armas, municiones y material de guerra; estas medidas no deberán alterar las condiciones de competencia en el mercado 
común respecto de los productos que no estén destinados a fines específicamente militares.»

El problema en este último punto estriba, naturalmente, en determinar qué es lo específicamente militar en un sector que nutre y se alimenta de toda la economía. Airbus y sus alrededor de 500 subcontratistas locales son de ello un buen ejemplo. En gran medida, gracias a la expansión prevista a raíz de la actividad manufacturera derivada concretamente del montaje del enorme A380, se estima que la población del Departamento del Alto Garona, cuya capital es la ciudad de Toulouse, cuartel general de la industria aeroespacial europea, pasará de poco más de un millón de habitantes en 1999 hasta los más de millón y medio en 2030. También EADS propiedad de la española Sociedad Estatal de Participaciones Industriales (SEPI) en un 5,6\% - tiene su casa matriz en Toulouse.

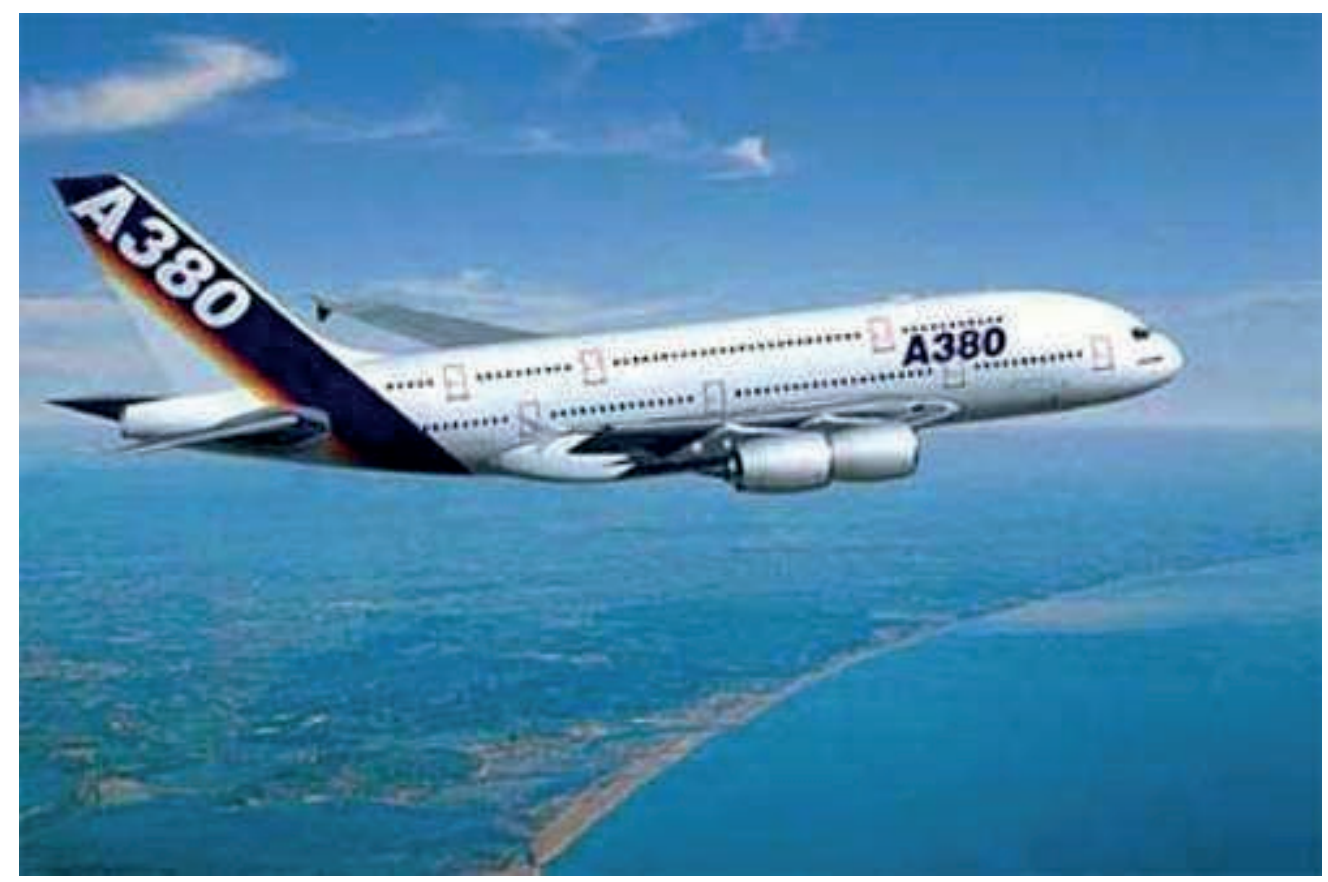




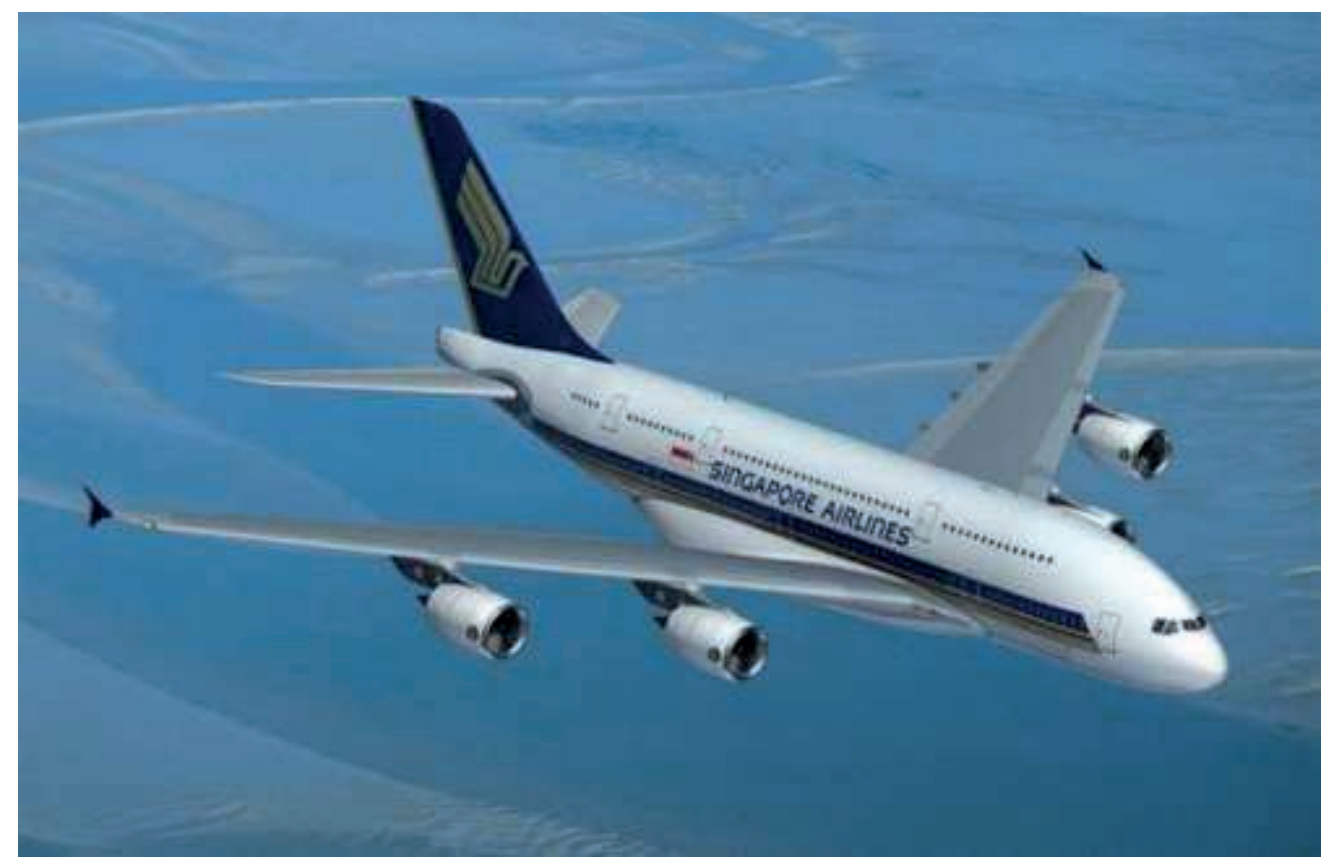

Por otro lado, ni la Unión Europea como entidad política independiente puede recaudar tributos $-\mathrm{y}$, sin potestad tributaria, no hay propiamente Estado-, ni tiene un Ejército capaz de hacer valer sus decisiones de política exterior, que han de ser, además, adoptadas, en última instancia, por los Estados miembros soberanos, y no por la Unión, que carece, hoy por hoy, de personalidad jurídica propia.

Estos dos rasgos, muy bien conocidos de todos, son fundamentales para comprender y caracterizar la economía y la política exterior de la Unión Europea. Un tercer rasgo sirve para situar adecuadamente la cuestión: el presupuesto de la UE está limitado en la práctica al 1\% de su renta nacional bruta (RNB) NOTA 2. El 15 de diciembre de 2003, los jefes de Estado y de Gobierno de seis países contribuyentes netos (Alemania, Reino Unido, Países Bajos, Francia, Suecia y Austria) solicitaron a la Comisión que no se superase ese límite. 


\section{PRESUPUESTO DE GASTOS}

\section{DE LA UNION EUROPEA EN 2005}

(Miles de millones de euros)

Agricultura

Ayuda regional

Ayuda y política exterior

Administración

Investigación

Otros

Total
49

32

8

6

4

7

106

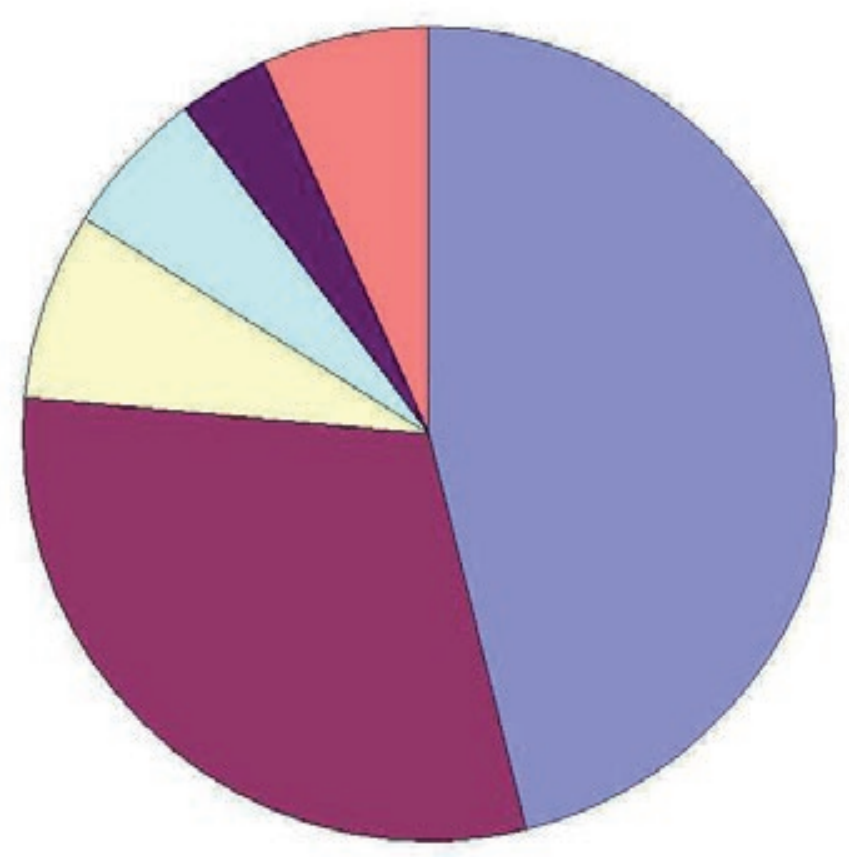

A Agricultura - Ayuda regional $\square$ Ayuda y politica exterior 口Admiristación - Imvestigación ㅁotros

Fuente: Elaboración propia a partir de British Broadcasting Corporation

En la ampliación de 2004, por la que se incorporaron a la UE dos islas (Malta y Chipre) más una franja de 8 países ex-comunistas -Estonia, Letonia, Lituania, 
Polonia, República Checa, Eslovaquia, Hungría y Eslovenia- que, junto con Rumanía y Bulgaria, dos estados de recentísima incorporación, recorre de norte a sur todo el continente que se extiende bajo Suecia y Finlandia, la agricultura y los fondos estructurales y de cohesión supusieron los capítulos más difíciles de la negociación. Se trata de las dos grandes partidas del presupuesto europeo. España, por ejemplo, máxima beneficiaria tradicional de la ayuda regional, se ha visto obligada a renunciar a una cantidad muy considerable de fondos estructurales y de cohesión, más por debilidad e imposiciones políticas que por generosidad desinteresada. Y Francia, que absorbe la mayor parte del presupuesto agrícola, ve con preocupación la nueva revisión de la Política Agraria Común (PAC) a que la ampliación, y previamente los propios compromisos franceses adquiridos en el seno de la Organización Mundial del Comercio (OMC), obligará, especialmente en lo que concierne a los pagos directos a sus agricultores.

Por otro lado, los mercados de capitales NOTA 3 de los distintos países son ciertamente dispares, tanto en tamaño como en estándares de transparencia y normas reguladoras. Lo cual obliga a homogeneizar las normas o a la especialización productiva. Los últimos movimientos de fusiones de plataformas bursátiles apuntan en este sentido. Financieramente, Londres, Frankfurt, París y Luxemburgo ruedan en cabeza. España, con su holding BME y su sistema de contratación SIBE, parece apostar por incrementar el volumen de negociación con Iberoamérica. Y no pertenece a Euronext, la sociedad que gestiona las Bolsas de París, Bruselas, Ámsterdam y Lisboa y el poderoso mercado de derivados de Londres. El pasado 1 de junio de 2006, se hizo oficial el acuerdo de fusión entre la Bolsa de Nueva York (NYSE) y Euronext por el que se puso en funcionamiento el primer mercado de valores trasatlántico del mundo. Dirigido por el presidente del grupo NYSE, John Thain -antiguo presidente de Goldman Sachs- y presidido por Jean-François Théodore, tiene su sede central en Nueva York y un valor en bolsa de 20.000 millones de dólares. NYSE Euronext da empleo a 1.259 personas, y el valor de mercado de las empresas allí cotizadas (su 
capitalización bursátil) asciende a la friolera de 21,5 trillones de euros. Adquirió, además, en 2005, en asociación con Borsa Italiana, una participación mayoritaria en MTS, el mercado electrónico líder de valores de renta fija al por mayor.

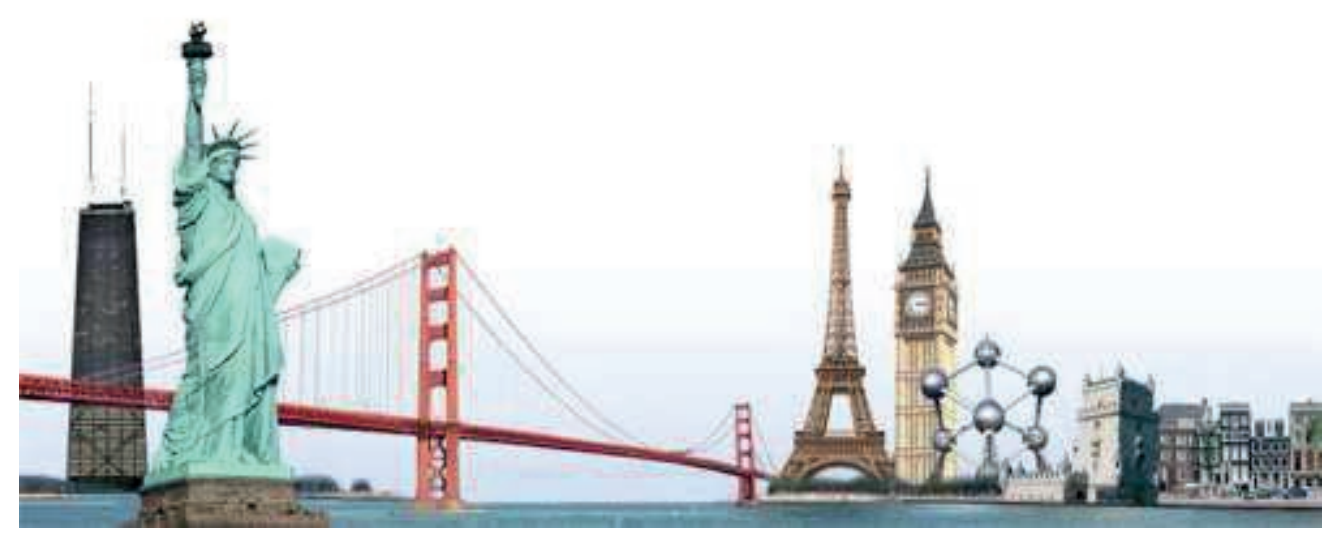

El 4 de abril de 2007 se inauguró oficialmente NYSE Euronext. Aglutina las bolsas de Nueva York, Ámsterdam, Bruselas, Lisboa, Oporto y París. Y el poderoso mercado de derivados de Londres.

Se trata, por tanto, del mercado de acciones mayor y más líquido NOTA 4 del mundo. Su volumen diario combinado de negociación asciende a unos 77.000 millones de euros (102.000 millones de dólares) (28 de febrero de 2007). Es, pues, una máquina de generar comisiones. Puede decirse que los 20.000 millones de dólares en los que se valoran las acciones que representan la propiedad de Euronext equivalen al valor actual de todas las comisiones que, previsiblemente, generará el intercambio de las acciones y títulos-valor que conforman el mercado, incluidos los productos derivados cuya existencia no está necesariamente materializada en documento alguno.

Estamos hablando de un mercado continuo en el que cotizan 3.565 empresas (7 españolas, 11 italianas y 18 francesas). 
Ya en 1993, la Mesa Redonda de Economistas Financieros (un grupo de veteranos economistas financieros de reconocido prestigio), tras su primera reunión, emitió un comunicado en el que instaba a los poderes públicos estadounidenses y a la comunidad financiera a eliminar las restricciones que dificultan a las empresas extranjeras cotizar y negociar sus acciones en los mercados de los EEUU: la globalización se manifiesta, por supuesto, también en los mercados financieros, dentro de los cuales las Bolsas son parte esencial, si bien no la más importante. El distinto tratamiento de las plusvalías dentro de Europa incide muy notablemente en la capitalización bursátil de las distintas Bolsas europeas. En este sentido, ya apuntaba el profesor Lagares en 1998 que dicha disparidad en el tratamiento de las ganancias de capital hacía que la actividad bursátil se desplegase muy principalmente en Frankfurt y que "aquí no [viésemos] una operación".

Los paraísos fiscales; las empresas $\mathrm{GmbH}$; el caso de Suiza, que no pertenece a la UE y que tiene relaciones muy especiales con Washington; y el secreto bancario del Estado Vaticano son piezas fundamentales de la arquitectura financiera europea, que aquí sólo dejamos anotadas sin mayor profundidad.

Finlandia tiene una economía de libre mercado muy industrializada con una renta per cápita aproximadamente igual a la del Reino Unido, Francia, Alemania e Italia. El sector manufacturero -principalmente madera, metales, ingeniería, telecomunicaciones e industrias electrónicas- es el más importante de su economía. $\mathrm{Su}$ comercio es importante (sus exportaciones suponen dos quintos de su PIB). Las exportaciones de productos de alta tecnología, tales como teléfonos móviles, son su mayor fortaleza. Finlandia depende de la importación de materias primas y energía, así como de ciertos bienes intermedios que necesita para la producción de bienes manufacturados. Debido a su clima, su agricultura apenas cubre sus propias necesidades de productos básicos. Pertenece a la Unión Económica y Monetaria 
(UEM) NOTA 5. Su elevado desempleo continúa siendo uno de sus mayores problemas.

La isla de Chipre está dividida administrativa y políticamente en una parte musulmana (la República Turca de Chipre del Norte, únicamente reconocida en Europa por Turquía) y en otra cristiana (la República de Chipre, en el sur de la isla), si bien la Unión Europea parece apostar por una homogeneidad en el futuro de ambas regiones -una comunión entre religiones- y recoge la información estadística correspondiente a ambas zonas en una cifra agregada. No así la CIA. Quizá la presencia de las bases militares británicas de Akrotiri y Dhekelia, y el hecho de que haya 3.500 efectivos del Reino Unido destacados en la isla tenga con ello algo que ver. Existen también dos zonas de amortiguación administradas por la ONU.

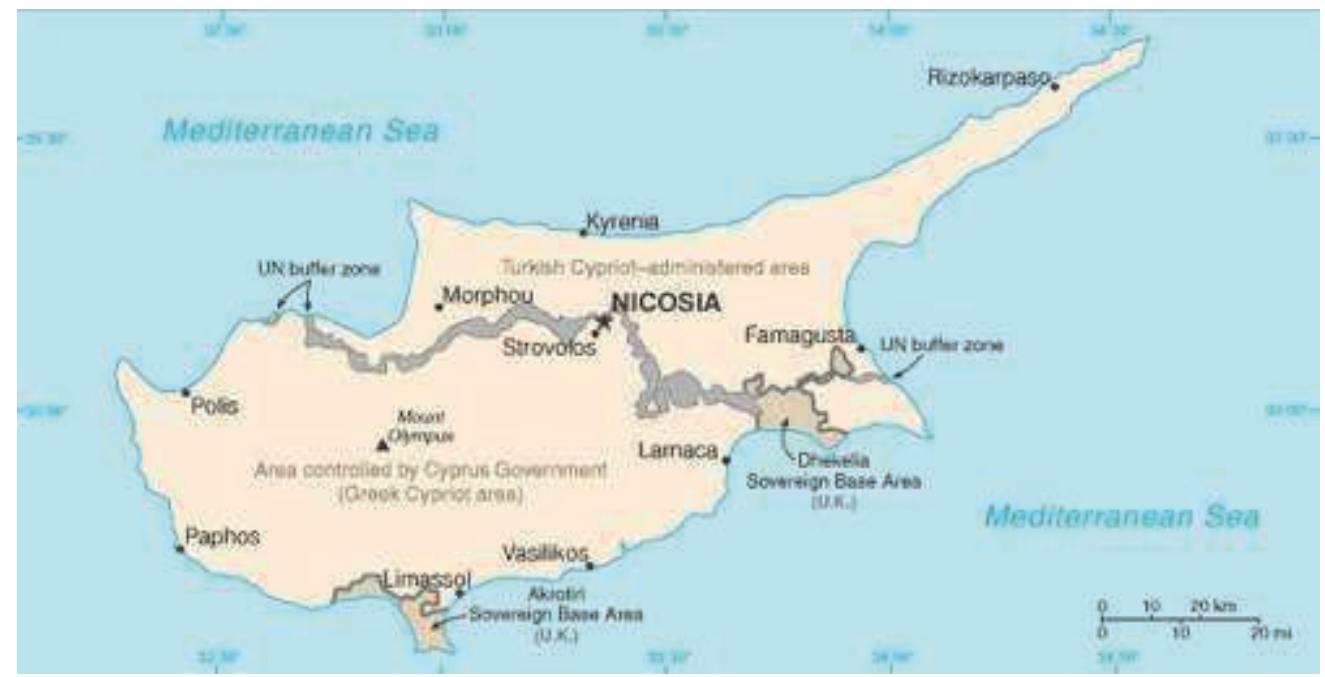

La República de Chipre tiene una economía de mercado dominada por el sector servicios, que supone el $76 \%$ de su PIB, en el que predominan el turismo y los servicios financieros. En mayo de 2005 se adhirió al Mecanismo de Tipos de Cambio II (MTC II NOTA 6). Con el fin de poder adoptar el euro el primero de enero de 2008, el Gobierno ha iniciado un agresivo programa de austeridad que ha conseguido reducir el déficit presupuestario por debajo del 3\% del PIB. Al igual que sucede en la 
zona administrada por los chipriotas turcos, la escasez de agua debida a pertinaces sequías es un problema perenne. Para hacerle frente, se están construyendo plantas potabilizadoras.

La economía chipriota turca tiene una renta per cápita de un tercio de la del sur. Su moneda es la lira turca. Se trata de una economía aislada por razones geográficas, y pequeña, que depende muy considerablemente de las transferencias del Gobierno turco y de las remesas que envían sus emigrantes empleados en el sur de la isla. (Según el protocolo económico de 2003-2006, Ankara tenía previsto aportar a la República Turca de Chipre del Norte unos 550 millones de dólares.)

Alemania es sin duda la economía más pujante de toda la Unión, si bien su tasa de crecimiento era hasta hace unos meses una de las más bajas de Europa, fundamentalmente debido al costoso proceso de modernización e integración de Alemania oriental (con transferencias anuales del orden de los 60.000 millones de euros, canalizados fundamentalmente a través del Banco Europeo de Reconstrucción y Desarrollo, el banco multilateral creado en 1990 para reformar el antiguo bloque comunista), así como a su carísimo sistema de pensiones y seguridad social, que hace que sus costes laborales se encuentren entre los más altos del mundo.

Esta situación ha podido traducirse en éxito económico indudable en la medida en que el gasto público ha redundado en la formación de una fuerza laboral cualificada capaz de mantener una permanente innovación técnica que ha situado al país durante años entre las principales potencias industriales exportadoras del mundo. Sin olvidar su notable estabilidad monetaria y política, en la que ha sido fundamental el buen entendimiento entre empresarios y trabajadores (moderados crecimientos salariales y continuos aumentos de la productividad); así como una población relativamente joven, que hoy ya no lo es tanto, y una tasa de desempleo no muy elevada. 
El envejecimiento de la población y el elevado desempleo han hecho que los pagos realizados por la seguridad social superen las contribuciones de los trabajadores en activo, situando el déficit público por encima del 3\% del PIB, y haciendo que Alemania incumpla flagrantemente el Pacto de Estabilidad y Crecimiento que ella misma diseñó e impuso a los demás. Sólo muy recientemente ha cambiado esta situación, que para muchos economistas no es especialmente preocupante, sino un fantasma de la República de Weimar.

La rigidez estructural del mercado de trabajo alemán, reflejada en la dificultad extrema para despedir trabajadores y en los convenios colectivos a nivel nacional como mecanismo de fijación de salarios (dos perversidades económicas evidentes que sólo pueden justificarse por razones políticas), han hecho del desempleo un problema crónico. La atención urgente de estos problemas, junto con la reestructuración empresarial y el desarrollo de los mercados de capitales se imponen como condiciones ineludibles para tratar de garantizar un cierto éxito frente al reto que la progresiva integración europea y la globalización presentan a la economía germana. Su producción industrial es importantísima (una de cada cinco máquinas producidas en el mundo en 2001 era alemana), y sus famosas empresas Mittelstand, negocios con menos de 1.000 trabajadores, son las principales responsables del éxito económico alemán.

Alemania tiene a Francia, Estados Unidos, Reino Unido, Italia, Países Bajos, Bélgica, Austria y España como principales socios exportadores. El 6,4\% de sus importaciones proceden de China, y sus importaciones industriales españolas son mínimas. El año pasado, no obstante, les ganamos el mundial de Fórmula 1, lo cual tiene importantes repercusiones económicas. Y el árbitro nos favoreció mucho menos que la suerte cuando todo apuntaba que podíamos ganarles en su casa también el mundial de 
balonmano, revalidando nuestro título de campeones del mundo logrado en Túnez en 2005.

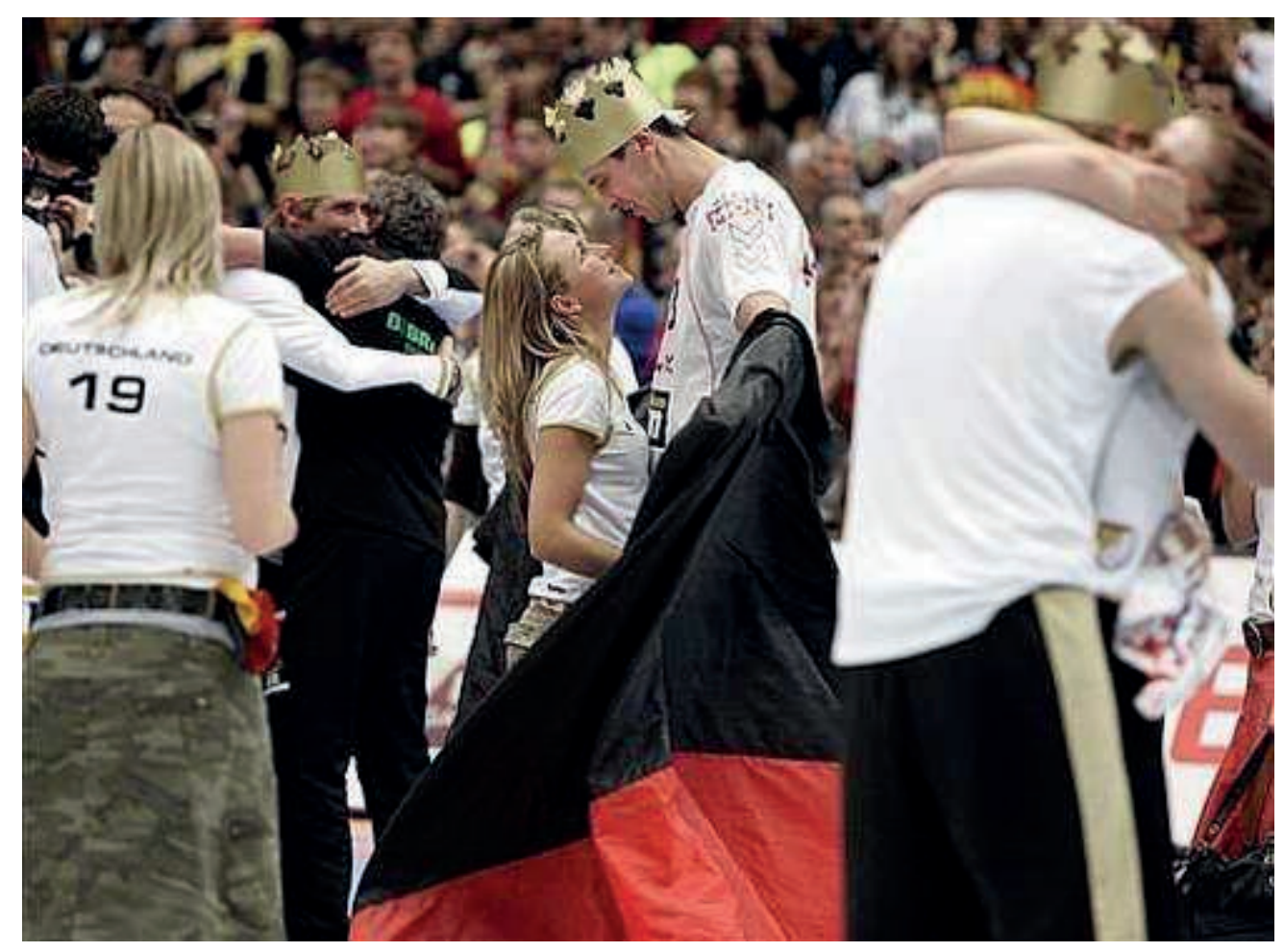

Alemania gana a Polonia 29 a 24 y se alza con el mundial del 2007 AP Photo/Martin Meissner 


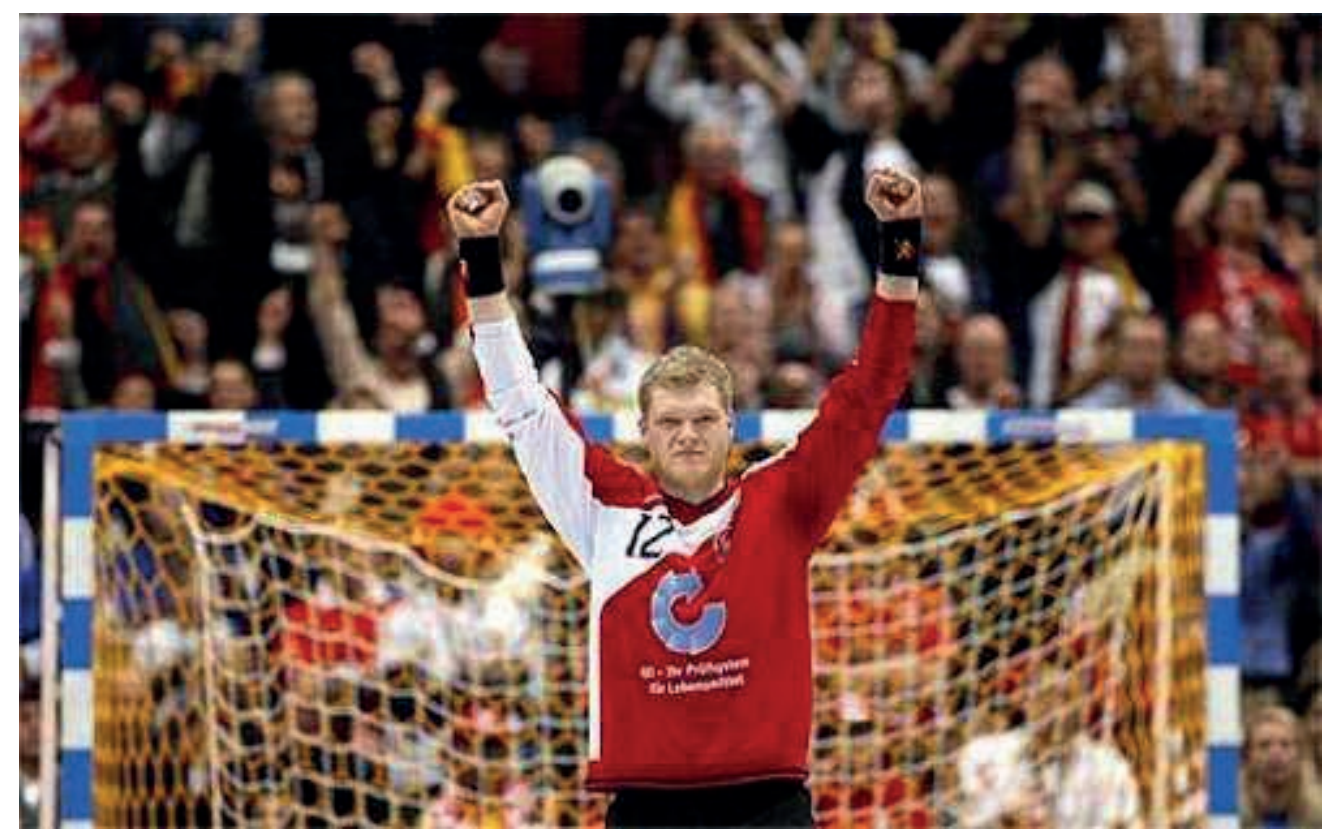

\section{$\underline{\text { ACCIONARIADO DEL BERD }}$}

Miembro

EE UU

Reino Unido

Japón

Italia

Alemania

Francia

Rusia

España

Canadá

Unión Europea

Banco Europeo de Inversión

Países Bajos
Capital suscrito

(millones de $€$ )

2.000

1.704

1.704

1.704

1.704

1.704

800

680

680

600

600

496 
Austria, Bélgica, Suecia, Suiza 456 each

PRINCIPALES ACCIONISTAS DEL BERD

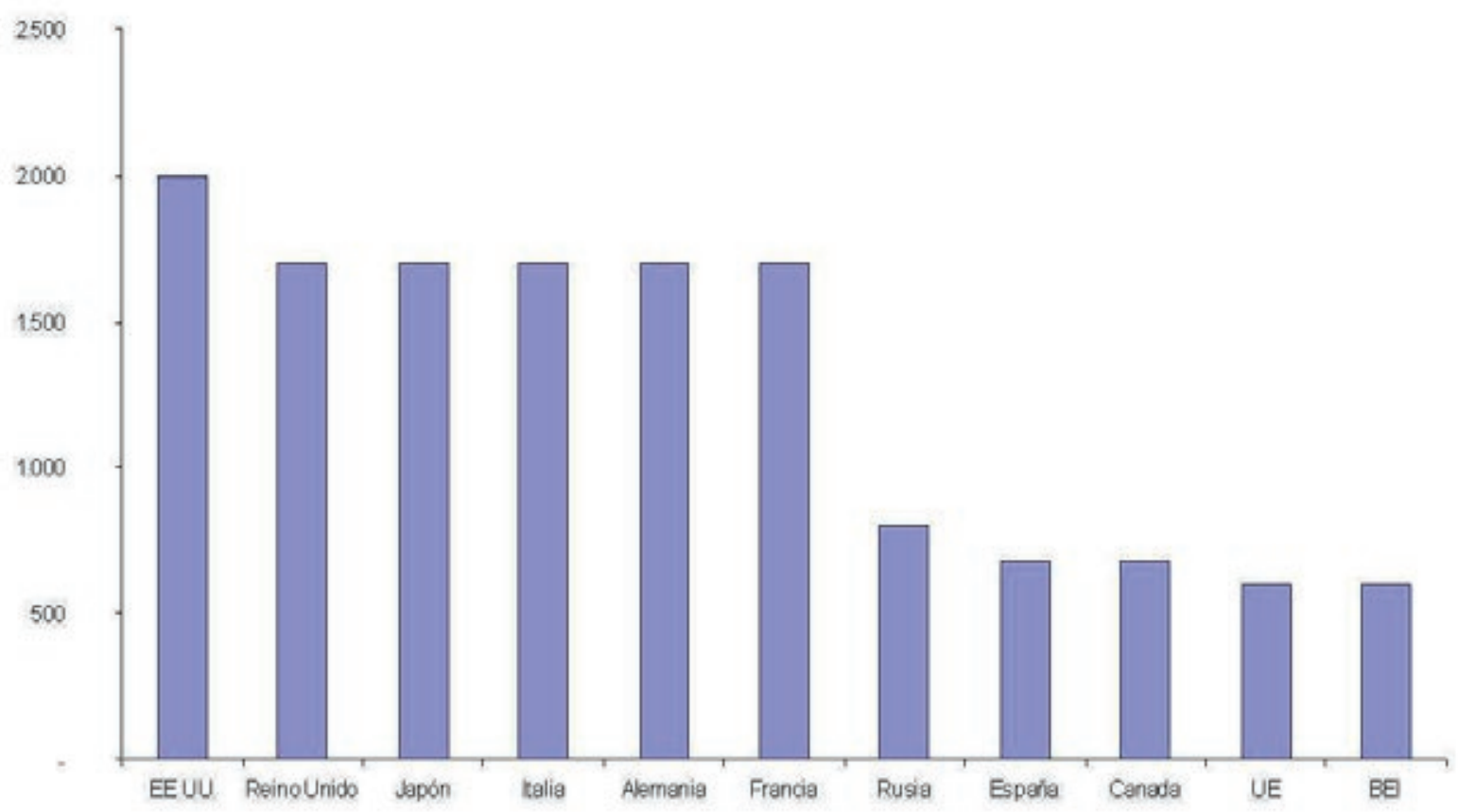

Fuente: Elaboración propia a partir de www.ebrd.org

\section{ALEMANIA}

Principales socios

Importadores

cuota $\%$

8,7

8,5

Países Bajos

6,6

China

6,4

Reino Unido

6,3

Italia

5,7
Principales socios

exportadores cuota $\%$

Francia $\quad 10,2$

Estados Unidos $\quad 8,8$

Reino Unido $\quad 7,9$

Italia $\quad 6,9$

Países Bajos $\quad 6,1$

Bélgica $\quad 5,6$ 


$\begin{array}{llll}\text { Bélgica } & 5 & \text { Austria } & 5,4 \\ \text { Austria } & 4 & \text { España } & 5,1\end{array}$

Fuente: Elaboración propia a partir de www.cia.gov

IMPORTACIONES ALEMANAS

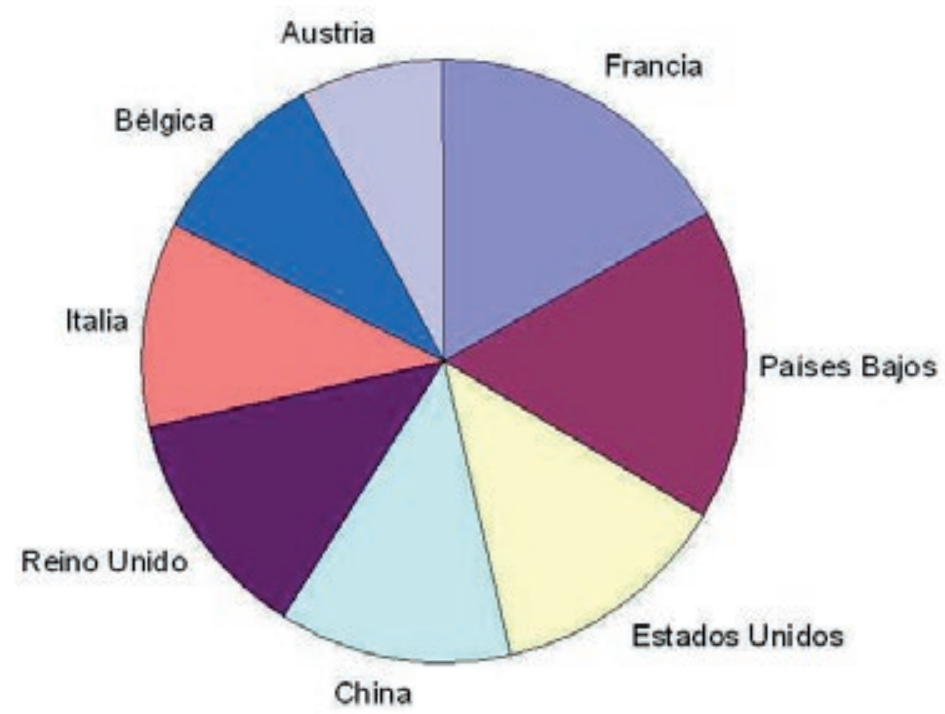




\section{EXPORTACIONES ALEMANAS}

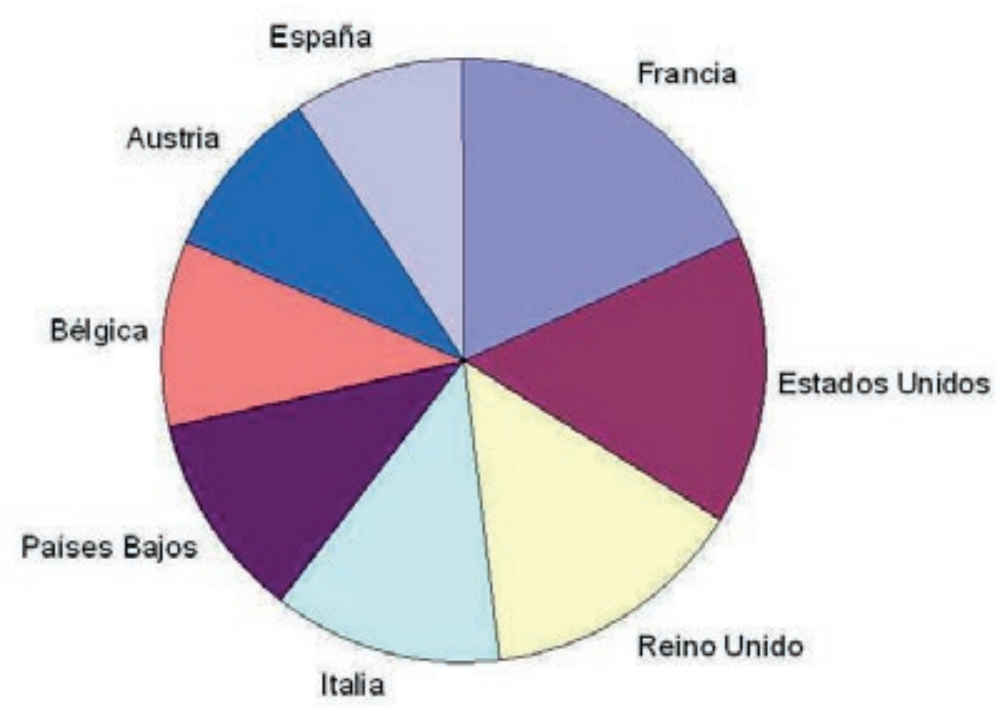

Sus relaciones financieras son, sin embargo, muy distintas a las estadounidenses y, en ese sentido, más parecidas estratégicamente a las francesas, lo cual explica sin duda el encontronazo provocado por la invasión de Irak. Es -junto con Francia, Reino Unido, China, Rusia y los EE UU- miembro permanente del Consejo de Seguridad de las Naciones Unidas. Tiene prohibida la producción de armas nucleares desde que el Canciller Adenauer adquiriera tal compromiso dejando el camino libre para que Alemania Occidental entrase a formar parte de la OTAN el 6 de mayo de 1955. 


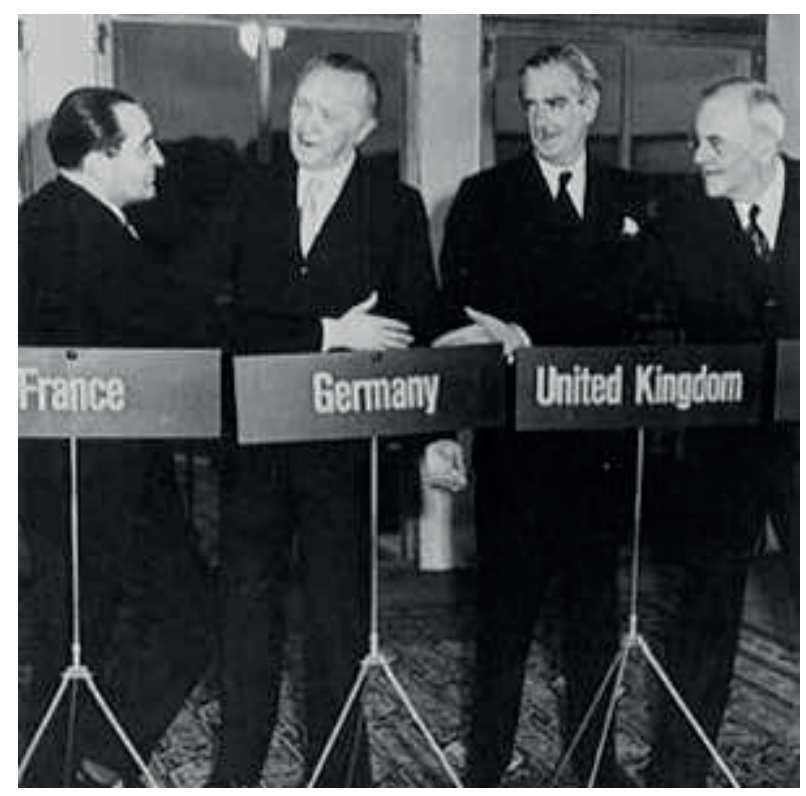

9 de mayo de 1955. Entrada en la OTAN

El país se divide en 16 estados federales. Baden-Wurtemberg -tierra natal de Einstein, del poeta Schiller y del filósofo Hegel-, cuya capital es Stuttgart, es el centro de la industria automovilística alemana. Allí tienen su cuartel general compañías como DaimlerChrysler, Audi o Porsche. Allí se ubican también Voith, el mayor productor mundial de maquinaria papelera, y Trumpf, que acapara la mitad del mercado europeo de maquinaria de elaboración de planchas metálicas. 


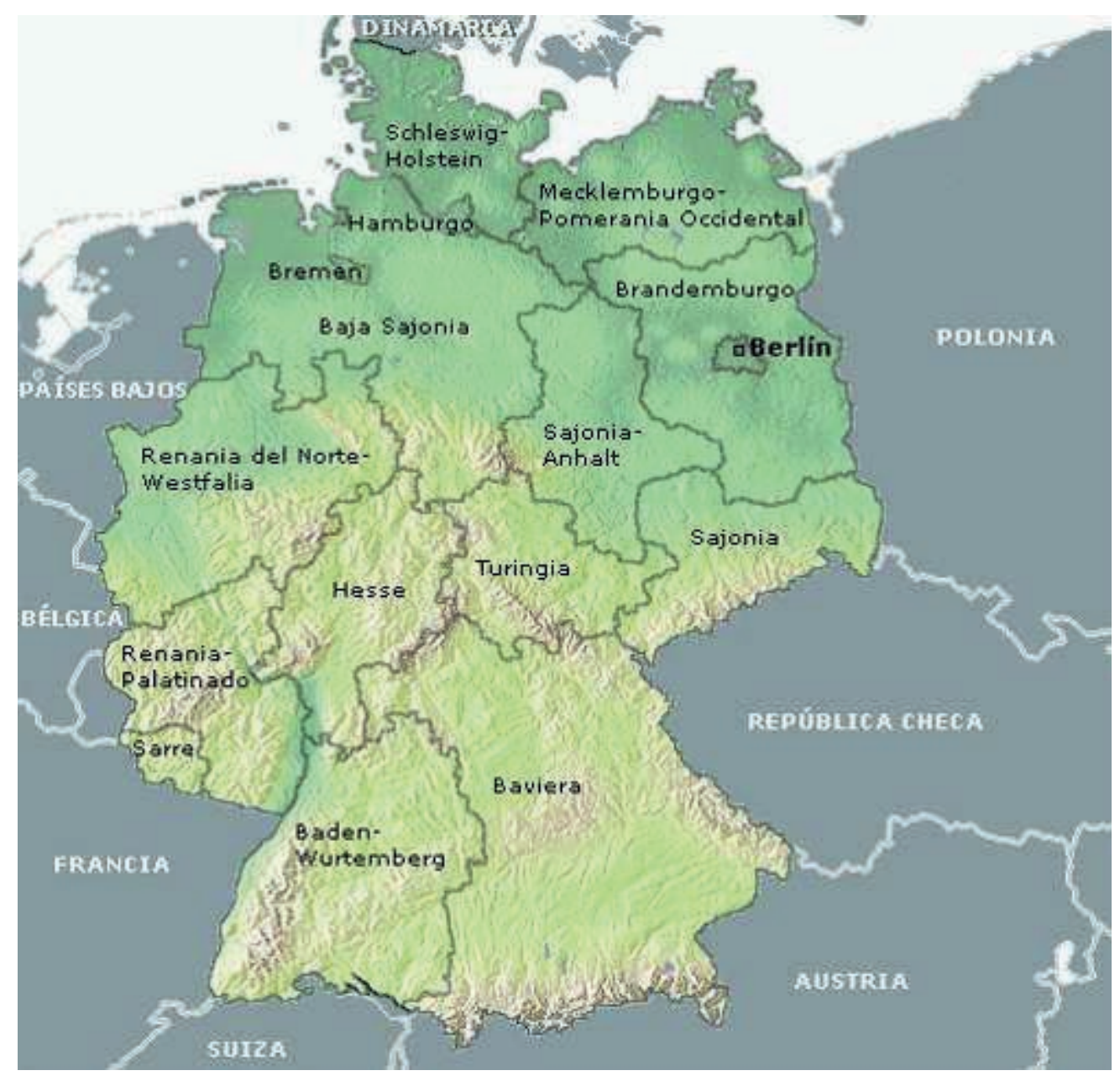

A su lado, España es un pálido reflejo, si bien en la pequeña villa industrial de Elgóibar, al calor de un régimen fiscal muy especial, se concentran veinte empresas productoras de maquinaria industrial ("máquina herramienta") en escasamente 50 km2; su producción representó en 2000 más de la mitad de la producción española del sector de máquinas herramienta, uno de los más dinámicos de la economía española. Elgóibar exporta más de la mitad de su producción y es un modelo de cluster industrial para el resto del mundo. 


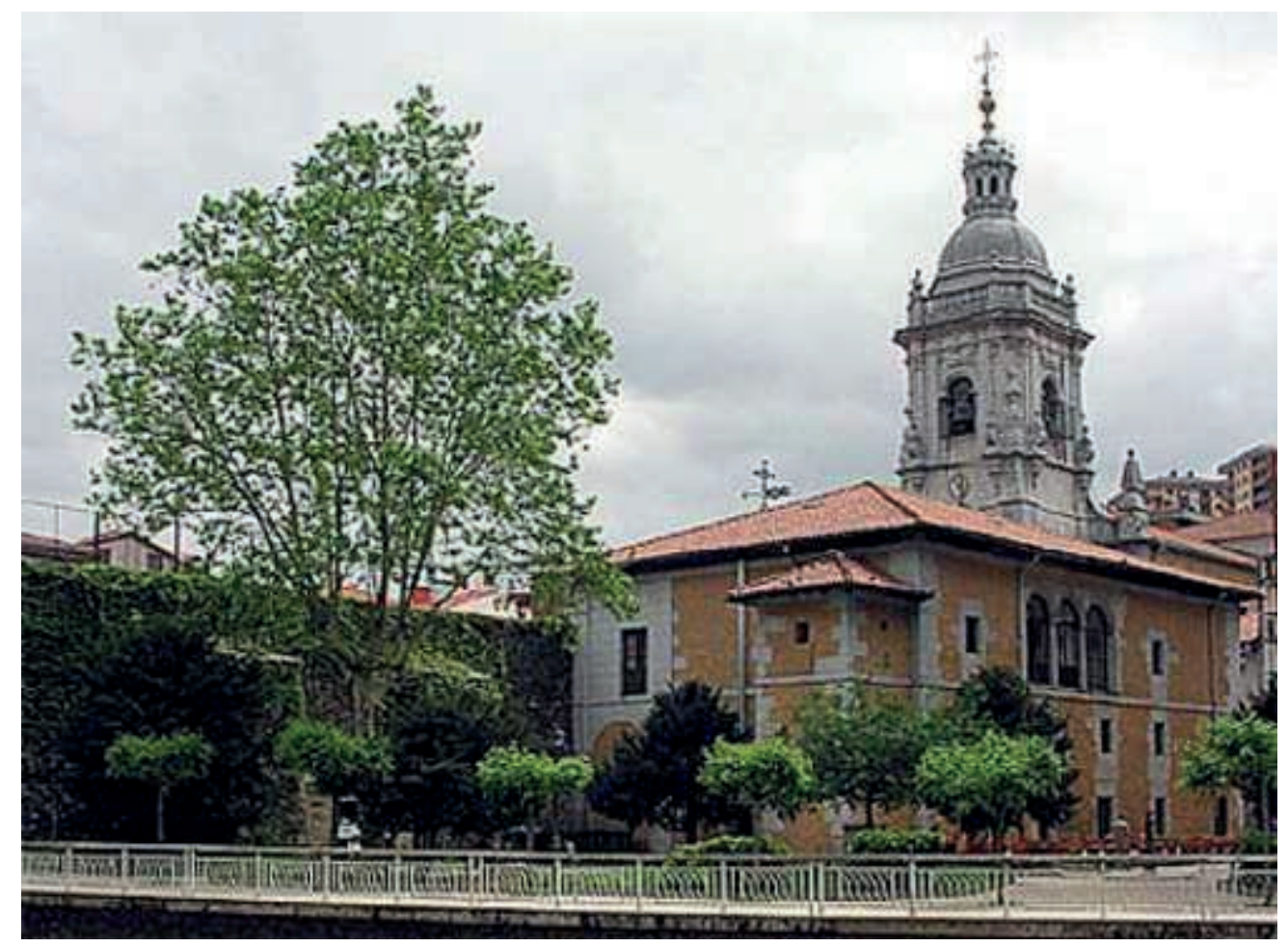

Elgóibar (Guipúzcoa) ESPAÑA

\section{ESTADOS FEDERADOS ALEMANES (LÄNDER)}

Land

Baden-Wurtemberg

Baviera

Berlín

Brandenburgo

Bremen

Hamburgo

Hesse
Capital

Stuttgart

Múnich

Berlín

Potsdam

Bremen

Hamburgo

Wiesbaden 
Mecklemburgo-Pomerania Occidental

Baja Sajonia

Renania del Norte-Westfalia

Renania-Palatinado

Sarre

Sajonia

Sajonia-Anhalt

Schleswig-Holstein

Turingia
Schwerin

Hanóver

Düsseldorf

Maguncia

Sarrebruck

Dresde

Magdeburgo

Kiel

Érfurt

Italia es una economía industrial, sobre todo en el norte del país, donde se asientan importantes empresas privadas, especialmente pequeñas y medianas empresas familiares especializadas en productos de diseño e ingeniería de vanguardia. En cuanto a las grandes empresas, hay que citar a Fiat, controlada por la familia Agnelli; Pirelli, controlada por los Pirelli; y Fininvest, controlada por el anterior primer ministro Silvio Berlusconi. Estas familias ejercen su control a través de sociedades de tenencia de valores y mediante participaciones cruzadas con aliados industriales y financieros, lo que les permite mantener la propiedad con participaciones reducidas.

La industria supone el 29\% del PIB italiano y cerca del 90\% de sus exportaciones de mercancías. El sur del país es más agrícola y dependiente del estado del bienestar y registra una tasa de desempleo cercana al 20 por ciento. (No se deje el lector seducir por la idea de que Estado del bienestar y tasa elevada de desempleo siempre van de la mano, aunque sea una verdad como un puño.)

La economía sumergida -localizada fundamentalmente en la agricultura, la construcción y los servicios- supone más del 20\% de la producción. El país importa la mayor parte de las materias primas que su industria necesita y más de tres cuartas partes de su energía. Su mafia es conocida en todo el mundo y participa muy 
activamente en la economía italiana y mundial. De modo que no cabe hablar de la economía italiana sin hablar de estos grupos mafiosos.

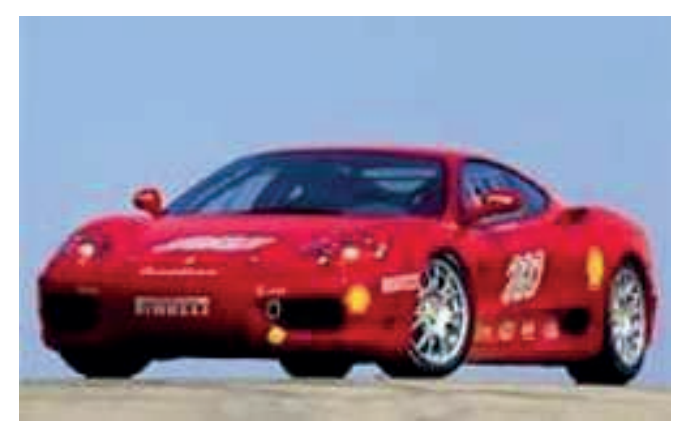

\section{Ferrari 360 Challenge}

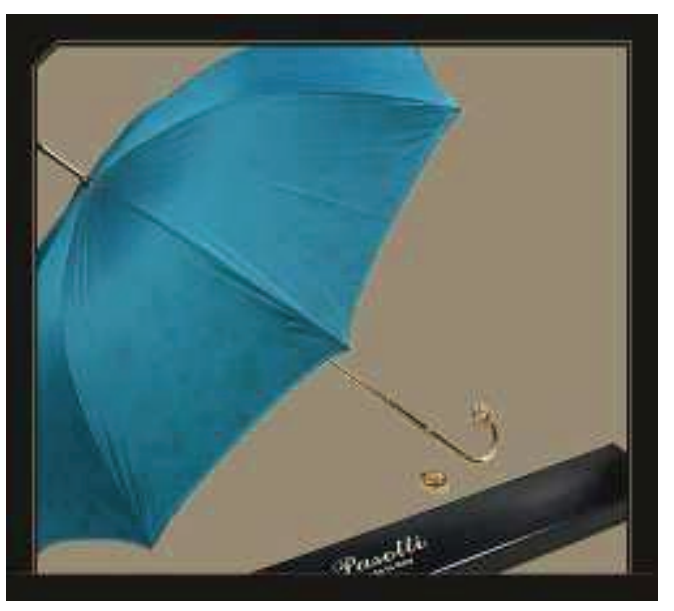

Pasotti ombrelli, desde 1956

Como le sucede a España, y a los países europeos en general, Italia necesita mejorar su competitividad y productividad si quiere lograr un cierto crecimiento a largo y medio plazo -no creció nada en 2005-, para lo que se hace preciso disminuir la carga o presión fiscal, liberalizar el mercado de trabajo y modificar su excesivamente generoso sistema de pensiones.

Se trata de las tantas veces citadas reformas estructurales, a las que, naturalmente, se oponen los sindicatos y los perceptores de pensiones. Desde 1993, los gobiernos italianos han llevado a cabo un importante programa de privatizaciones y, en la 
última década, han tenido que practicar una política fiscal restrictiva para formar parte de la UEM.

Italia se ha beneficiado desde la introducción del euro de bajos tipos de interés y de una moderada inflación. Nadie duda de que con tipos más altos habría sido imposible para el Gobierno italiano -con una deuda del 106\% de su PIB en 2005atender cumplidamente el servicio de su deuda, situando al país en una peligrosísima situación fiscal, que le obligaría a acometer reformas y a sortear muchas crisis políticas, que muy bien podrían dar al traste con el euro. Tampoco se discute que la inflación no sería tan moderada si incluyésemos en su cómputo el precio de las acciones -múltiplo elevado del valor en libros de las empresas- y el de los inmuebles, que esconde una muy abundante financiación crediticia y deducciones fiscales capitalizadas.

Como sucede en casi todas partes, los bajos tipos de interés y el gasto público corriente (transferencias) que buscan un mayor crecimiento económico pueden muy bien acabar traduciéndose en tipos de interés reales negativos, y en superiores niveles de endeudamiento y de crecimiento de los precios, sobre todo de algunos de ellos. (Esta es sin duda una de las razones por las cuales el BCE ha ido elevando los tipos en los últimos trimestres.) Pero consiguen, en parte, mantener los niveles de empleo y evitar la justamente temida deflación, aunque sea a costa de ahogar la tasa de crecimiento de la producción.

Todo esto denota sencillamente que las posibilidades de invertir con rentabilidad (las oportunidades rentables de inversión) en Europa son escasas -la liquidez muy abundante, repiten con frecuencia los analistas financieros-, dados los elevados costes laborales, que lo son por hallarse desvinculados de la productividad individual y por tratarse de gastos consolidados. 
La fijación de salarios según convenios colectivos y no según la productividad individual de cada trabajador es un mecanismo político para resolver un problema económico. El resultado elemental es que se evita una crisis sindical o política -que no social- y se distribuye la renta a costa de una mayor inflación y menor nivel de empleo y ahorro, pues la tasa de inflación tiende a situarse por encima de la remuneración del ahorro. Este último rasgo es, junto con la más igualitaria distribución de la renta, la imagen de marca europea, desde luego la española, que nos diferencia del tan denostado como desconocido "modelo americano", en el que la tasa de inflación tiende a ser inferior a los tipos de interés, el nivel de empleo muy superior al europeo, y en el que se considera que la "mala" distribución de la renta es un acicate constante que estimula la innovación y la asunción de riesgos empresariales.

Tasas de inflación inmobiliaria más elevadas que el coste del dinero disparan las cotas de endeudamiento y merman el caudal del ahorrador. Ello importa poco cuando el sistema estatal de financiación de las pensiones es de reparto y no de capitalización, pero puede ser fatal cuando, por razones demográficas, dicho sistema de reparto deja de ser un mecanismo eficaz de financiación de las pensiones. Este es uno de los retos fundamentales a los que se enfrenta la economía de la UE en un futuro muy próximo.

\section{FONDOS DE PENSIONES: ACTIVOS TOTALES}

(Miles de millones de euros)

$\begin{array}{lllll}\text { PAÍ́s } & 2000 & \% / \text { total } & 2002 & \% / \text { total } \\ \text { Alemania } & 331 & 13,34 & 354 & 16,65 \\ \text { Austria } & 25 & 0,99 & 16 & 0,75 \\ \text { Bélgica } & 15 & 0,58 & 13 & 0,63 \\ \text { Dinamarca } & 42 & 1,69 & 42 & 1,98\end{array}$




$\begin{array}{lllll}\text { España } & 42 & 1,71 & 46 & 2,15 \\ \text { Finlandia } & 12 & 0,47 & 11 & 0,52 \\ \text { Francia } & 92 & 3,71 & 47 & 2,23 \\ \text { Grecia } & 5 & 0,20 & \text { n. d. } & \text { n. d. } \\ \text { Países Bajos } & 445 & 17,91 & 436 & 20,50 \\ \text { Irlanda } & 53 & 2,11 & 45 & 2,11 \\ \text { Italia } & 30 & 1,21 & 34 & 1,62 \\ \text { Luxemburgo } & 0,0474 & 0,002 & \text { n. d. } & \text { n. d. } \\ \text { Portugal } & 13 & 0,53 & 16 & 0,75 \\ \text { Reino Unido } & 1240 & 49,92 & 950 & 44,65 \\ \text { Suecia } & 140 & 5,62 & 116 & 5,47 \\ \text { Total } & 2.484 & & 2.127 & \end{array}$

FOIID OS DE PEIISIOIIES DE LA UHIOII EUROPEA AIIIO 2000 (Miles de nillones de euros)

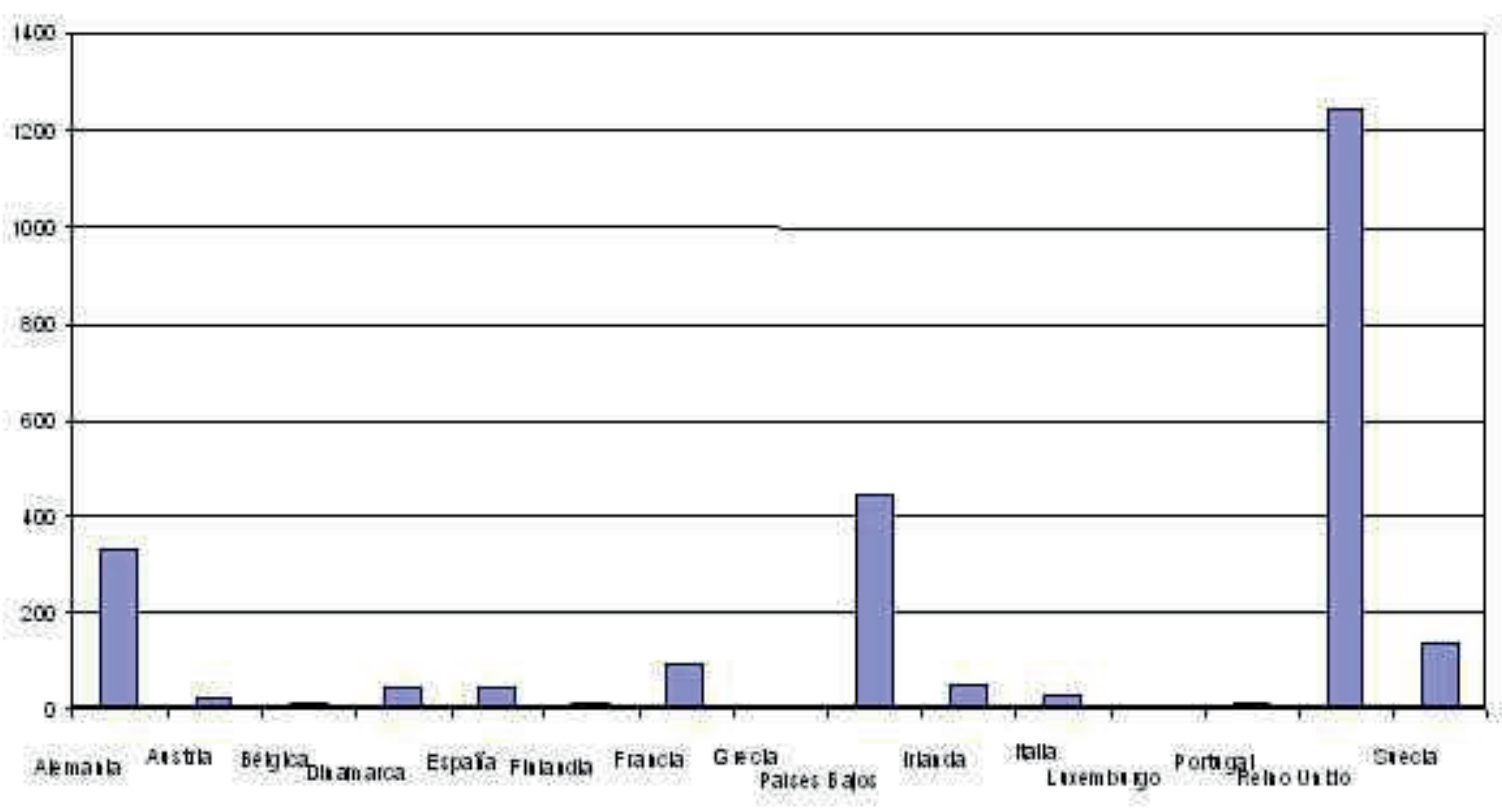

Fuente: www.efrp.org 


\section{POBLACIÓN DE LA UNIÓN EUROPEA EN 2005}

País

$\mathrm{N}^{\mathrm{o}}$ de habitantes

Superficie/km2

personas / km2

\begin{tabular}{|c|c|c|c|}
\hline Alemania & 82.500 .800 & 357.021 & 231 \\
\hline Austria & 8.206 .500 & 83.870 & 98 \\
\hline Bulgaria & 10.379 .067 & 110.910 & 340 \\
\hline Bélgica & 10.445 .900 & 30.528 & 342 \\
\hline Chipre & 749.200 & 9.250 & 81 \\
\hline Dinamarca & 5.411 .400 & 43.094 & 126 \\
\hline Eslovaquia & 5.384 .800 & 48.845 & 110 \\
\hline Eslovenia & 1.997 .600 & 20.273 & 99 \\
\hline España & 43.038 .000 & 504.782 & 85 \\
\hline Estonia & 1.347 .000 & 45.226 & 30 \\
\hline Finlandia & 5.236 .600 & 338.145 & 15 \\
\hline Francia & 60.561 .200 & 547.030 & 111 \\
\hline Grecia & 11.075 .700 & 131.940 & 84 \\
\hline Hungría & 10.097 .500 & 93.030 & 109 \\
\hline Irlanda & 4.109 .200 & 70.280 & 58 \\
\hline Italia & 58.462 .400 & 301.230 & 194 \\
\hline Letonia & 2.306 .400 & 64.589 & 36 \\
\hline Lituania & 3.425 .300 & 65.200 & 53 \\
\hline Luxemburgo & 455.000 & 2.586 & 176 \\
\hline Países Bajos & 16.305 .500 & 41.526 & 393 \\
\hline Malta & 402.700 & 316 & 1.274 \\
\hline Polonia & 38.173 .800 & 312.685 & 122 \\
\hline Portugal & 10.529 .300 & 92.391 & 114 \\
\hline Reino Unido & 60.034 .500 & 244.820 & 245 \\
\hline República Checa & 10.220 .600 & 78.866 & 130 \\
\hline
\end{tabular}




$\begin{array}{lcll}\text { Rumanía } & 22.303 .552 & 237.500 & 94 \\ \text { Suecia } & 9.011 .400 & 449.964 & 20 \\ \text { Total } & 492.170 .919 & 4.325 .897 & \\ \% \text { / total mundial } & 13 & 3 & \end{array}$

Fuente: Eurostat y CIA

\section{POBLACIÓN DE LA UNIÓN EUROPEA EN 2005}

(Por tramos de edad)

\begin{tabular}{|c|c|c|c|}
\hline País & $\begin{array}{l}N^{o} \text { de menores } \\
\text { de } 15 \text { años }\end{array}$ & $\begin{array}{l}\text { Población } \\
\text { entre } 15 \text { y } 64\end{array}$ & $\begin{array}{l}N^{0} \text { de mayores } \\
\text { de } 64 \text { años }\end{array}$ \\
\hline Alemania & 11.639 .408 & 37.305 .555 & 16.018.097 \\
\hline Austria & 1.259 .939 & 5.532 .332 & 1.400 .609 \\
\hline Bulgaria & 1.729 .353 & 6.840 .444 & 1.809 .270 \\
\hline Bélgica & 1.030 .215 & 5.075 .734 & 1.279 .418 \\
\hline Chipre & 160.048 & 533.608 & 90.645 \\
\hline Dinamarca & 1.019 .954 & 3.602 .646 & 828.061 \\
\hline Eslovaquia & 909.271 & 3.877 .183 & 652.994 \\
\hline Eslovenia & 278.129 & 1.417 .343 & 314.875 \\
\hline España & 5.822 .011 & 27.405.389 & 7.170 .442 \\
\hline Estonia & 200.954 & 895.714 & 227.665 \\
\hline Finlandia & 894.139 & 3.491 .532 & 4.337 .233 \\
\hline Francia & 11.131 .365 & 39.746 .734 & 9.998 .037 \\
\hline Grecia & 1.533 .193 & 7.128 .348 & 2.026 .517 \\
\hline Hungría & 1.554 .552 & 6.909 .015 & 1.517 .767 \\
\hline Irlanda & 847.677 & 2.744 .223 & 470.335 \\
\hline Italia & 8.047 .129 & 38.636 .353 & 11.450 .027 \\
\hline
\end{tabular}




$\begin{array}{llll}\text { Letonia } & 317.653 & 1.584 .046 & 373.036 \\ \text { Lituania } & 555.346 & 2.476 .099 & 554.461 \\ \text { Luxemburgo } & 89.474 & 315.573 & 69.366 \\ \text { Países Bajos } & 68.632 & 276.657 & 54.925 \\ \text { Malta } & 2.960 .513 & 11.181 .929 & 2.349 .019 \\ \text { Polonia } & 6.119 .174 & 27.290 .069 & 5.127 .626 \\ \text { Portugal } & 1.754 .608 & 7.029 .219 & 1.822 .043 \\ \text { Reino Unido } & 10.579 .377 & 19.988 .959 & 5.477 .226 \\ \text { República Checa } & 1.469 .801 & 7.285 .057 & 1.480 .597 \\ \text { Rumanía } & 3.507 .102 & 15.521 .433 & 3.275 .017 \\ \text { Suecia } & 1.508 .206 & 5.920 .170 & 1.588 .220\end{array}$

Fuente: Elaboración propia a partir de CIA

Nota: El dato correspondiente a España es ¡tres millones! inferior a la cifra española oficial.

La escasez de oportunidades rentables de inversión es una de las tres restricciones fundamentales de cualquier economía, siendo las otras dos la restricción financiera y la de demanda. La restricción financiera consiste en no poder disponer de financiación para un proyecto rentable, capaz de contribuir al crecimiento económico (entendido como mayor o mejor producción de bienes y servicios, no como mero aumento del nivel de empleo). La restricción de demanda consiste en la imposibilidad de saber con certeza cuál será el nivel de demanda futuro, con lo que resulta imposible saber si un proyecto supuestamente rentable lo acabará siendo realmente. $Y$, por lo tanto, no se puede saber a ciencia cierta si conviene o no relajar la restricción financiera que atenaza un proyecto empresarial. Una decisión política acaba resolviendo este problema irresoluble, y convierte a los responsables políticos en agentes económicos. De ahí la importancia de la banca de inversión y de las 
finanzas. Baste, en este sentido, recordar cómo Wall Street apoyó ampliamente al Presidente Bush en 2000 y 2004.

\section{MIEMBROS DE LA COMISIÓN EUROPEA (2004-2009)}

Nombre País Cargo Área de competencia

José Manuel Durão Barroso Portugal Presidente

Margot Wallström Suecia Vicepresidente Relaciones

institucionales y comunicación

Günter Verheugen Alemania Vicepresidente Empresa e industria

Jaques Barrot Francia Vicepresidente Transporte

Siim Kallas Estonia Vicepresidente Asuntos

administrativos, auditoría y lucha contra el fraude

Franco Frattini Italia Vicepresidente Justicia, libertad y seguridad

Viviane Reding Luxemburgo Comisario Sociedad de la información y medios de comunicación

Stavros Dimas $\quad$ Grecia Comisario Medio ambiente

Joaquín Almunia España Comisario Asuntos económicos y

monetarios 
Danuta Hübner

Joe Borg

marítimos

Dalia Grybauskaité

y presupuestos

Janez Potocnik

Ján Figel'

cultura y multilingüísmo

Marcos Kyprianou

los consumidores

Olli Rehn

Louis Michel

humanitaria

László Kovács

aduanera

Neelie Kroes

Mariann Fischer Boel

rural
Polonia Comisario Política regional

Malta Comisario Pesca y asuntos

Lituania Comisario Programación financiera

Eslovaquia Comisario Educación, formación,

Chipre Comisario Sanidad y protección de Finlandia Comisario Ampliación

Bélgica Comisario Desarrollo y ayuda Hungría Comisario Fiscalidad y unión Países Bajos Comisario Competencia

Dinamarca Comisario Agricultura y desarrollo 
Benita Ferrero-Waldner

Austria Comisario Relaciones exteriores y política europea de vecindad

Charlie McCreevy Irlanda Comisario Mercado interior y servicios

Vladimír Špidla República Checa Comisario Empleo, asuntos sociales e igualdad de oportunidades

Peter Mandelson Reino Unido Comisario Comercio
Andris Piebalgs
Letonia
Comisario Energía

Fuente: Elaboración propia a partir de Eurostat

El débil crecimiento económico de 2001-05 ha supuesto un serio deterioro de las cuentas públicas italianas. Un rasgo compartido con Francia y Alemania. Y, ahora que el BCE ha vuelto a elevar los tipos de interés, el Gobierno español ha manifestado su intención de fijar por ley el precio de las hipotecas, al igual que hace con la energía eléctrica o con las tasas académicas. Una pincelada más de estatificación, que nos acerca al centro político, ese lugar en el que se vive sin demasiada pena y sin demasiada gloria también, y que, en nuestra opinión, es otro primer jalón para que el euro continúe siendo lo que siempre ha sido: una patata europea. Eso sí, una patata muy rica y valiosa que ha costado mucho conseguir y que conviene cuidar.

Vayamos ahora con la tercera de las cuatro grandes economías de la Unión. 
Según los datos de Comisión Europea, la economía francesa es la segunda más importante de Europa occidental, con un peso equivalente a tres cuartas partes del correspondiente a la economía alemana, que es la principal. Y muy poco por encima de la británica. En cambio, según los datos de la CIA, en dólares, la economía francesa es casi 150.000 millones de euros (aproximadamente el PIB de Portugal o Irlanda) menos importante que la británica. Podría pensarse que este hecho estadístico se debe a la utilización de un tipo de cambio que sobrevalora la libra esterlina. Sin embargo, lo mismo sucede respecto de la economía alemana: hay una disparidad de 200.000 millones de euros, que no cabe atribuir al tipo de cambio oficial aplicado, pues tal disparidad no existe en el caso de Francia ni en el de Italia. Cuando se trata de datos de PIB según la paridad del poder adquisitivo -que trata de recoger el hecho de que 100 euros en Madrid duren menos que 100 euros en Tallin y más que 100 euros en Frankfurt- las disparidades son exageradas.

La economía francesa destaca por su diversificación. Al igual que hiciera el Reino Unido, Francia apostó tras la segunda guerra mundial por un modelo económico en el que se pensaba que "las cosas irían mejor en la medida en que la Administración, vía impuestos y nacionalizaciones, controlase porcentajes crecientes de la riqueza nacional, que en ningún caso debían quedar por debajo del cincuenta por ciento de la misma" (Muñoz-Alonso, 2005, p. 306). Así que los monopolios estatales -el transporte ferroviario, la energía, las telecomunicaciones...-, tan cuestionados y debatidos hoy, son un rasgo distintivo de la economía francesa. Su sistema de pensiones y su elevado gasto sanitario se consideran del todo insostenibles, dado el envejecimiento de su población. Su mercado de trabajo es un ejemplo para el mundo de diseño económico patológico. Su agricultura absorbe la mayor parte de la partida más importante del presupuesto de la Unión, con pagos directos a sus agricultores cuantificados en torno a los 10.000 millones de euros al año, que se reparten entre el $20 \%$ de los agricultores, grandes terratenientes. Francia es el cuarto mayor exportador mundial de bienes, y el tercero si nos ceñimos a los servicios. Aun así, su 
saldo por cuenta corriente de 2005 fue negativo y cercano a los 30.000 millones de euros, aproximadamente el 2\% de su PIB. En los últimos años, ha venido registrando superávit en su balanza de servicios y de rentas, y déficit en su balanza comercial.

Tras un periodo de paz y neutralidad bélica durante todo el siglo XX, la economía sueca disfruta de un envidiable nivel de vida. Su sistema económico es una combinación de capitalismo de alta tecnología y de generalizados beneficios sociales. Es, en este sentido, muy parecido al sistema belga y al danés. Cuenta con un moderno sistema de distribución, excelentes comunicaciones interiores y exteriores y una fuerza de trabajo muy bien preparada. Las empresas privadas son las responsables del $90 \%$ de la producción industrial, en la que la ingeniería supone la mitad de la producción y de las exportaciones. La madera, la energía hidráulica y la metalurgia del hierro constituyen la base de una economía muy orientada hacia el sector exterior, como indica su importante superávit por cuenta corriente, el más cuantioso de toda la Unión, sólo por detrás de Alemania y de los Países Bajos. Lo cual ayuda sin duda a entender las razones por las que Suecia mantiene su moneda y su soberanía monetaria. El objetivo principal del Riksbank es la estabilidad de precios, que trata de conseguir fijándose una tasa de inflación del 2\%. (Nótese que la tasa de inflación sueca es la más baja de toda la Unión, sólo igualada por Finlandia.) $\mathrm{Su}$ generoso sistema de pensiones está causando a los suecos serios problemas de incentivos, pues demasiada gente decide acogerse a las prestaciones por enfermedad, resintiéndose gravemente la actividad productiva.

La economía británica forma parte del tradicional cuarteto de economías de más de un billón de dólares de Europa occidental que España acaba de convertir en quinteto. En las dos últimas décadas el Gobierno británico ha reducido mucho la propiedad pública y ha contenido la expansión de los programas de bienestar social. No obstante lo cual, David Smith nos recuerda en The Sunday Times del 4 de febrero de 2007 que «el déficit presupuestario "estructural" es el quinto más grande de la 
OCDE». Ya escribía Ortega en su admirable y palpitante capítulo XIII de uno de sus libros más célebres que "el inglés quiere que el Estado tenga límites". Posición de plena actualidad, cuando se discute en Bruselas y en todo el mundo la estructura futura del Presupuesto de la Unión.

El Reino Unido es un centro financiero de primer orden. La banca, los seguros y los servicios profesionales generan la mayor parte del PIB británico. Su agricultura, muy mecanizada e intensiva, es muy eficiente. Produce el $60 \%$ de los alimentos que demanda el país empleando a menos del $2 \%$ de la población activa.

Tiene importantes reservas de carbón, gas natural y petróleo.

$\mathrm{Su}$ industria ha perdido peso específico en las últimas décadas. Los ingleses son conscientes de que una gran compañía industrial situada en Europa occidental es inviable a largo plazo, debido a los elevados costes de producción a los que se enfrenta. La solución consiste en entrar en mercados de bajo coste y altas expectativas de crecimiento: Rusia, China, la India y Brasil (los famosos BRICs). Por ello, la propiedad de la base industrial británica se halla cada vez más en manos extranjeras. Importa, no obstante, señalar que toda empresa extranjera suele contar entre sus propietarios con súbditos británicos.

España es considerada como una de las economías más dinámicas de Europa. Su PIB acaba de rebasar el billón de dólares.

Contamos, además, con los dos mayores clubes de carretera de Europa: el Dallas y el Madam's.

Aunque aparentemente su estructura económica es bastante parecida a la de los grandes países europeos, se trata de una economía semicapitalista, con un sector 
agrícola abultado y un peso muy importante del sector turístico. Subsisten en la economía española abundantes ineficiencias y regulaciones excesivas, que se traducen en falta de competitividad, como pone de manifiesto su preocupante déficit por cuenta corriente, una tasa de inflación muy elevada y una considerable tasa de desempleo. Por no hablar de nuestra escasísima productividad.

España tiene problemas de suministro energético y escasez de agua, pero cierra centrales nucleares. Se enfrenta a riesgos relacionados con un eventual colapso del mercado inmobiliario, y su notable tasa de crecimiento está bastante relacionada con los fondos estructurales y de cohesión que hasta ahora ha recibido de la Unión Europea y con los que no podrá contar en el futuro.

El prestigioso economista escocés John Kay, siguiendo sólo en parte la tradición positivista y empirista británica que cabe sintetizar en la famosa afirmación de Lord Kelvin "no hay ciencia sin medida", que es desde su creación en 1932 el lema de la Comisión Cowles -"Science is Measurement"-, concluye en una de sus investigaciones que "lo característico de la actividad fiscal hoy es elevar los impuestos de algunos productos para subvencionar otros, o gravar a ciertos individuos para otorgar a otros concesiones" (Kay, J. A., 1990). He aquí por qué muchos cuestionamos, con Frank Knight y James Buchanan, la teoría de los bienes públicos y la indiscutible conveniencia de una sanidad y una educación pública y obligatoria, en detrimento de la iniciativa privada en estos dos ámbitos fundamentales. Creemos que Alemania, que acaba de elevar su tipo general de IVA tres puntos, del $16 \%$ al 19\%, ha hecho una apuesta clarísima sobre qué tipo de financiación conviene más a la eficiencia económica. 

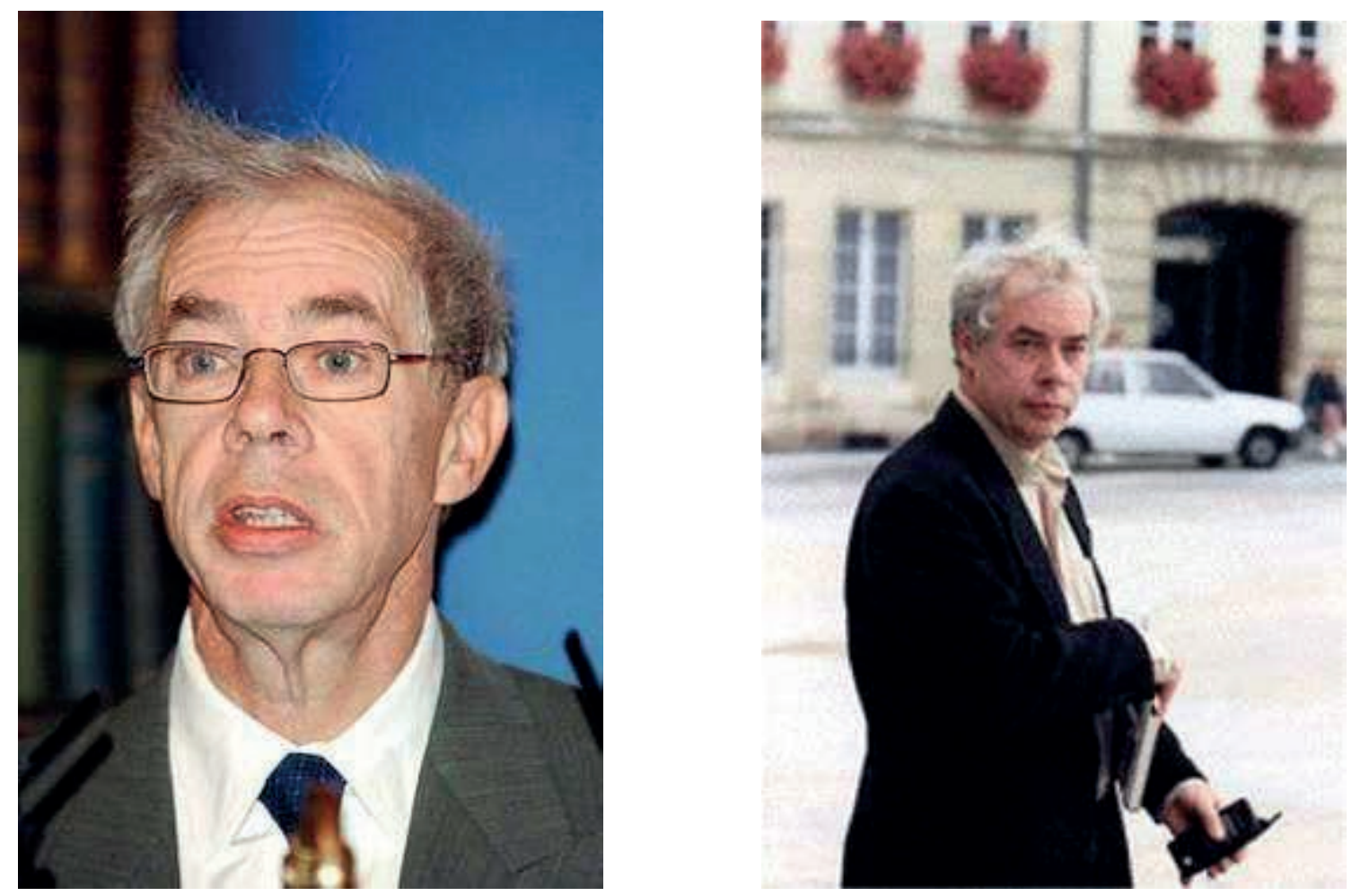

John Kay www.johnkay.com

Hasta qué punto la actividad financiera británica off shore es más importante que la capitaneada por la Ciudad del Vaticano, siendo un dato fundamental para estudiar la economía y la política exterior de la Unión, no es cuestión fácil de dilucidar, y requiere un estudio en profundidad de Mónaco, Andorra, Liechestein, San Marino y las islas del Canal (Jersey, Guernsey y Alderney), entre otros; y no sólo de Gibraltar, ¡español!

Al igual que en el caso de España, desde que en 1986 pasase a formar parte de la entonces Comunidad Económica Europea (CEE), la economía portuguesa se ha desarrollado enormemente, diversificándose y aumentando el tamaño de su sector servicios. También al igual que en el caso español o inglés, en la última década, los distintos gobiernos han procedido a liberalizar sectores económicos fundamentales, que Francia, por ejemplo, se resiste a liberalizar, tales como las telecomunicaciones, la energía y el sector financiero. Tal proceso privatizador y el consiguiente 
adelgazamiento del déficit público supuso en su momento elevadas tasas de crecimiento animadas por una considerable inversión directa extranjera (IDE).

La renta per cápita portuguesa equivale a dos tercios de la de las cuatro grandes economías de la Unión: Alemania, Reino Unido, Francia e Italia. Su poco desarrollado sistema educativo ha supuesto una traba para un mayor crecimiento de la productividad. Su ventaja competitiva se ve amenazada por los menores costes laborales y fiscales de Europa oriental y de Asia, que hacen de estas regiones polos de atracción para la IDE. Es este, indudablemente, un rasgo común a toda la UE, pero que afecta más directamente a aquellos países con un sector industrial menos desarrollado. El crecimiento de la población y su grado de especialización productiva marcarán en el porvenir -obvio es decirlo- el ritmo de crecimiento del PIB de cada país, y pondrán de manifiesto hasta qué punto el modelo económico europeo supone un acierto o un fraude.

En otro orden de cosas, a fecha de hoy, resulta obvio que la dependencia defensiva de Europa con respecto a los EEUU es casi total, lo que en muy buena medida explica la actitud antibelicista de la Europa actual, como tan acertadamente ha explicado Robert Kagan. 


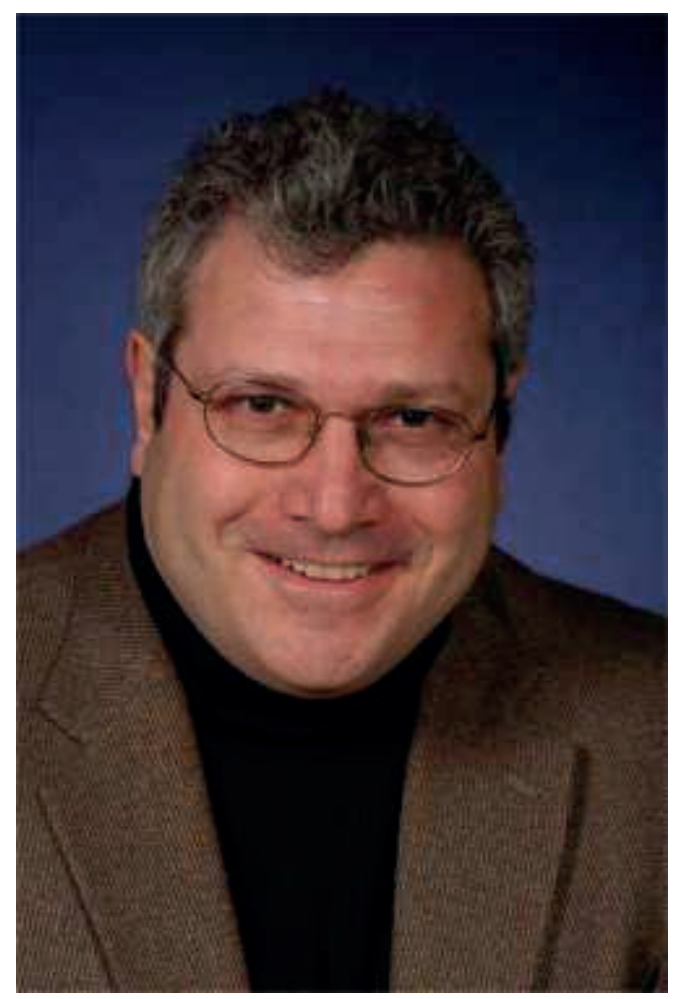

Robert Kagan

(The Carnegie Endowment for International Peace)

Algo muy parecido puede decirse con respecto a los mercados financieros, sobre todo si nos referimos a los mercados de productos derivados y a la banca de inversión. Dejando a un lado a Deutsche Bank -Alemania es la economía industrial de la Unión- y al banco suizo UBS, ningún banco europeo continental desempeña papel imprescindible alguno en el sistema financiero mundial. Para desempeñarlo, tendría que estar presente en China y en los Estados Unidos, y tener un mercado de derivados muy desarrollado. Ésta fue una de las razones por las que Santander inició en 1988 su alianza estratégica con The Royal Bank of Scotland, y por las que hoy, tras haber realizado la mayor inversión en metálico de la historia de una empresa española en los en Estados Unidos (2.265 millones de euros), pelea por sus derechos de voto en Sovereign. 
La entrada en el mercado chino era imposible desde España, un país de escasa relevancia política, económica y militar.

No estamos hablando aquí de exportación de bienes de consumo, como nuestros ahora italianos- famosos Chupa Chups, sino de un sector estratégico en el que ninguna empresa se instala sin el beneplácito, y hasta la connivencia, de las autoridades políticas.

El ámbito natural de expansión de un banco español, parecieran pensar los máximos responsables financieros del mundo, está en Iberoamérica y en el sector de banca de consumo. La banca industrial, la banca de inversión son negocios de concepción y ejecución mundial o planetaria, una de las tres púas del tridente del Presidente del Imperio de Occidente. Dinero, diplomacia y poderío militar son tres ases del Poseidón NOTA 7 americano. El cuarto as lo encontramos en la que es desde 1956 la divisa de su moneda: In God We Trust.

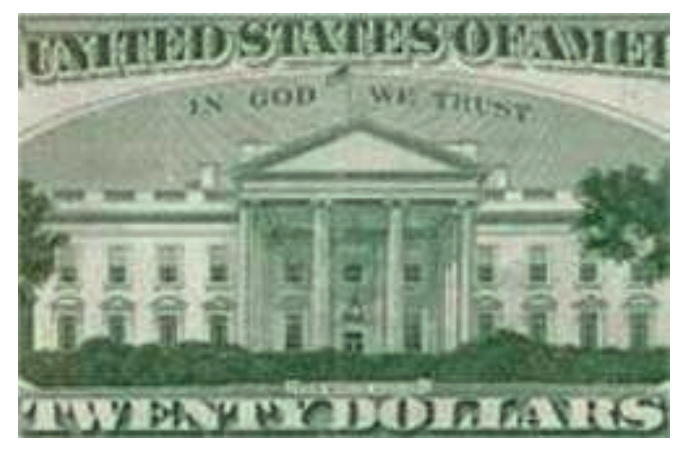

Sin embargo, no está escrito todavía que los españoles no seamos capaces de ganar, contra todo pronóstico, cuota de mercado en Miami; y hasta de recuperar Luisiana, arrancada por Napoleón a Carlos IV por el tratado secreto de San Ildefonso (1 de octubre de 1800). 


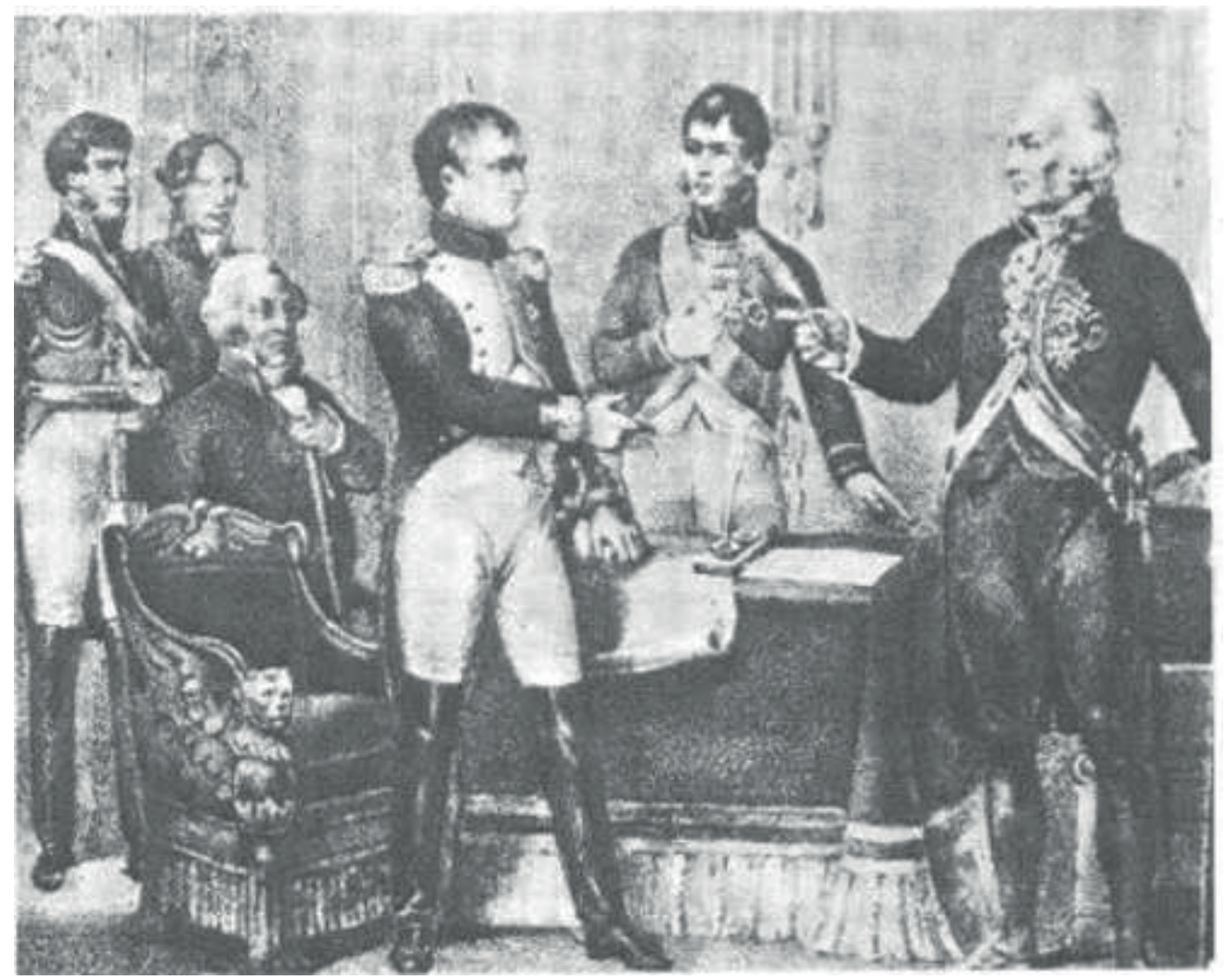

Abdicaciones de Bayona (1808): Carlos IV cede a Napoleón sus derechos dinásticos. Lo mismo había hecho previamente Fernando VII

Polonia mantuvo a lo largo de la década de los noventa una política de liberalización económica que permitió el crecimiento del sector privado empresarial, hoy todavía sujeto a muchas trabas administrativas que se manifiestan en un muy deficiente marco legal y corrupción generalizada. Su sector agrícola se ve aquejado de exceso de trabajadores, ineficiencia de las pequeñas empresas y falta de inversión. Se ha detenido la incipiente reestructuración y privatización de los "sectores delicados" (carbón, siderurgia, ferrocarriles, energía...). Las reformas a que se ha sometido la educación, la sanidad, las pensiones y la propia Administración se han traducido en una presión fiscal mayor de lo esperado, lo que obliga a reducir las pérdidas de las empresas estatales polacas, eliminar concesiones y privilegios y revisar a fondo el sistema fiscal con el fin de que aflore la economía sumergida y se fiscalice también a los agricultores, que hoy apenas tributan. 
A Lituania y Letonia les afectó mucho la crisis financiera rusa de 1998. Ambos países se recuperaron aumentando sus exportaciones occidentales y disminuyendo su dependencia de Rusia, acometiendo privatizaciones masivas con ayuda extranjera aquí aparece de nuevo el BERD y la banca de inversión americana-, si bien en el caso letón el Estado todavía es propietario de participaciones importantes en algunas grandes empresas.

\section{ESTRUCTURA ECONOMICA DE LA UNION EUROPEA POR SECTORES EN 2005}

País

$$
\text { \%PIB Agricultura }
$$

$\%$ PIB Industria

$\%$ PIB Servicios

$\begin{array}{llll}\text { Alemania } & 1,1 & 29,6 & 69,5 \\ \text { Austria } & 1,8 & 30,4 & 67,8 \\ \text { Bélgica } & 1,0 & 24,0 & 75,0 \\ \text { Bulgaria } & 9,3 & 30,4 & 60,3 \\ \text { Chipre } & 7,2 & 20,2 & 73,0 \\ \text { Dinamarca } & 1,8 & 24,6 & 73,5 \\ \text { Eslovaquia } & 3,5 & 29,4 & 67,2 \\ \text { Eslovenia } & 2,8 & 36,9 & 60,3 \\ \text { España } & 4,0 & 29,5 & 66,5 \\ \text { Estonia } & 4,1 & 29,1 & 66,8 \\ \text { Finlandia } & 2,8 & 29,5 & 67,6 \\ \text { Francia } & 2,2 & 21,4 & 76,4 \\ \text { Grecia } & 5,4 & 21,3 & 73,3 \\ \text { Hungría } & 3,9 & 30,9 & 65,3 \\ \text { Irlanda } & 5,0 & 46,0 & 49,0 \\ \text { Italia } & 2,1 & 29,1 & 68,8 \\ \text { Letonia } & 15,0 & 25,0 & 60,0\end{array}$




$\begin{array}{llll}\text { Lituania } & 5,5 & 32,5 & 62,0 \\ \text { Luxemburgo } & 1,0 & 13,0 & 86,0 \\ \text { Malta } & 3,0 & 23,0 & 74,0 \\ \text { Países Bajos } & 2,1 & 24,4 & 73,6 \\ \text { Polonia } & 5,0 & 31,1 & 64,0 \\ \text { Portugal } & 5,3 & 27,4 & 67,3 \\ \text { Reino Unido } & 0,5 & 23,7 & 75,8 \\ \text { República Checa } & 3,4 & 39,3 & 57,3 \\ \text { Rumanía } & 10,1 & 30,7 & 37,7 \\ \text { Suecia } & 1,1 & 28,2 & 74,0 \\ \text { Media } & 4,1 & 28,2 & 67,1\end{array}$

Fuente: CIA

\section{Bibliografía}

BANCO DE ESPAÑA (2005): La política monetaria en la zona del euro (Glosario)

CARRERA PONCELA, A. (2005): "¿Mercado único europeo con 25 impuestos de sociedades diferentes? La disparidad fiscal en España ante su devenir en la Unión Europea" Boletín de Estudios Económicos, Vol. LX núm. 185, agosto, pp. 229-250.

ESCUDERO PRADO, M $M^{a}$ E. (Coord.) (2004): Mercado de capitales europeo: El camino de la integración, Netbiblo, La Coruña.

GARCÍA DELGADO, J. L. (1998): Ejercicios y prácticas de economía española (3ª ed.). Cívitas, Madrid. 
KAGAN, R. (2002): "Power and Weakness", Policy Review, No. 113 (June and July 2002)

KAGAN, R. (2003): Poder y debilidad. Taurus Ediciones, Madrid.

LOZANO IRUESTE, J. Ma (2005): Diccionario Bilingüe de Economía y Empresa (inglés-español, español-inglés), (7ª edición). Ediciones Pirámide, Madrid.

MARIN ALAFONT, A. (2004): "Construcción europea. Entrevista especial a S.A.R. Otto de Habsburgo", Estrategia Global, núm. 4

MELGAREJO, J. (2002): "Sistemas complementarios de previsión social en el mercado único", Economía Exterior, núm. 20

MORÉ, I (2003): "Atlas mundial de financiación internacional", Análisis del Real Instituto Elcano.

MORÉ, I (2006): "Rusia abre la caja de Pandora del gas", Análisis del Real Instituto Elcano, núm. 5/2006.

MUÑOZ-ALONSO, A. (2005): "Mi descubrimiento personal de Raymond Aron", En Raymond Aron: Un liberal resistente, José María Lasalle (Coord.), FAES, Madrid.

Pitman Pocket Dictionary of Business Terms (1986): John Old, Tony Shafto and Lun Wong. London, UK.

Política Exterior, Vol. VI, núm. 29 (Otoño 1992): "Breve Diccionario del Tratado de la Unión Europea".

TAMAMES, R. (1998): Unión Monetaria y Euro: La recta final, Espasa, Madrid. 
TAMAMES, R. (Coord.) (2000): Economía según los expertos: una visión global, Ediciones 2010, Madrid.

TORREBLANCA, J. I. (2005): "Las perspectivas financieras 2007-2013 de la Unión Europea: un buen acuerdo para España." Análisis del Real Instituto Elcano.

TORREBLANCA, J. I. (2005): "Las perspectivas financieras 2007-2013 de la Unión Europea: Europa se amplía, el presupuesto se reduce." Análisis del Real Instituto Elcano.

\section{NOTAS}

NOTA 1 Décret n 2005-1739 du 30 décembre 2005

NOTA 2 El Diccionario de la Real Academia Española define la renta nacional bruta como el "conjunto de los ingresos derivados de la participación en el proceso productivo durante un año, y referido a una entidad nacional". Equivale al producto interior bruto (PIB), que es el valor monetario de todos los bienes y servicios producidos dentro de un país en un periodo de tiempo determinado, siempre y cuando se resten las rentas de residentes extranjeros y se añadan las obtenidas por residentes nacionales titulares de bienes o derechos situados en el exterior.

Cuando de una magnitud bruta se resta o deduce la cantidad correspondiente a la depreciación del capital utilizado en la producción (nótese que un coche nuevo no vale lo mismo al salir de fábrica que tras haber estado un año rodando, cuando sus ruedas y su motor están algo gastados), se obtiene una magnitud neta. Por otro lado, ciertos bienes de capital (el capital intelectual, en concreto) valen más, y no menos, 
tras haberse empleado para producir. Kenneth J. Arrow denominó learning by doing a este fenómeno.

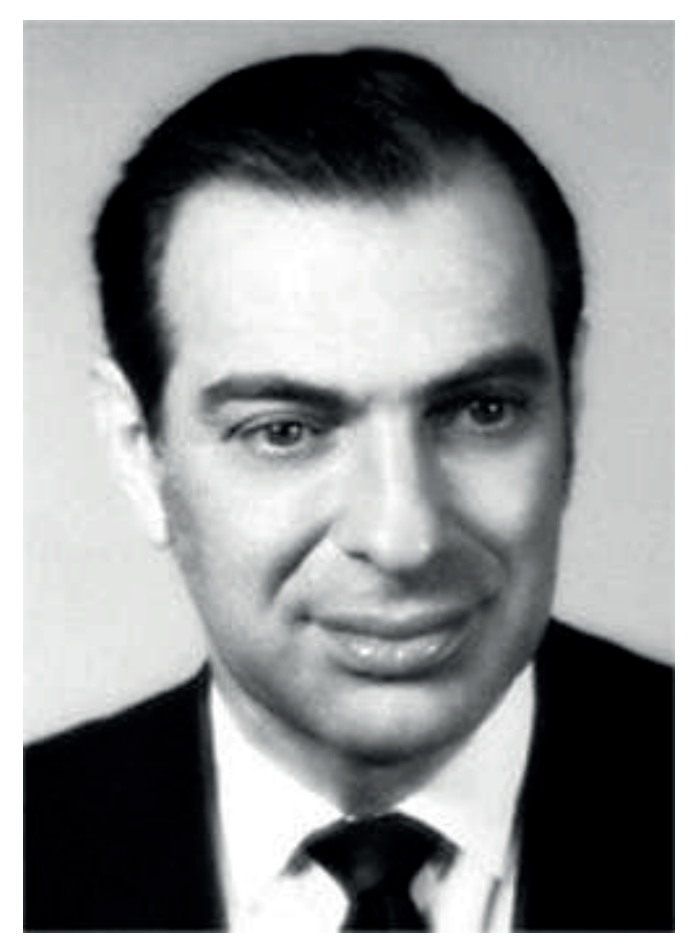

Kenneth J. Arrow (Nueva York, 1921)

Premio Nobel de Ciencias Económicas en 1972

NOTA 3 Conjunto de mercados financieros en los que se intercambian activos caracterizados por su amortización a medio y largo plazo. Incluye el mercado de valores y el mercado de créditos a medio y largo plazo, si bien únicamente el primero funciona en la práctica como un mercado abierto y organizado (García Delgado [Dir.], 1998, p. 109).

NOTA 4 Liquidez: Capacidad para hacer frente rápidamente a las obligaciones financieras (Lozano Irueste)

Liquidity: The quality of being liquid (easily convertible to cash) wWw.investorwords.com 
Liquid assets: Assets are said to be liquid when they can be swiftly and surely converted to cash or spendable bank credit. (Pitman)

NOTA 5 Proceso de integración de los Estados de la Unión Europea que comparten una misma moneda, el euro, y una política monetaria única (Banco de España, 2004, p. 86).

NOTA 6 Marco de cooperación en materia cambiaria entre la zona del euro y los Estados de la Unión Europea que no se han integrado en ella. Fue establecido por el Consejo Europeo el 16 de junio de 1997, para sustituir al mecanismo de cambios del Sistema Monetario Europeo en la tercera fase de la UEM. Su objetivo es mantener lo más estables que pueda los tipos de cambio entre los Estados de la UE que han adoptado el euro y los que todavía no lo han hecho, evitando, en lo posible, desajustes en los tipos de cambio reales o fluctuaciones excesivas en los tipos de cambio nominales que puedan producir perturbaciones en el comercio y afectar al buen funcionamiento del mercado único (Banco de España, 2004, p. 73).

NOTA 7 Neptuno (Poseidón, en griego), hijo de Saturno y Cibeles, es hermano de Júpiter y Juno. Es el rey de los mares que gobierna con su tridente, regalo de los cíclopes. Como Apolo, participó en la construcción de las murallas de la Troya de Laomedonte, pero este no le pagó el salario convenido. De aquí vendrá su rencor hacia Troya y, durante la guerra, tomó partido por los griegos, aunque con cierta imparcialidad (Eneida, p. 95, edición y traducción de Alfonso Cuatrecasas, Espasa, Madrid, 1951). 